\title{
AS MODALIDADES DA AVALIAÇÃO E AS ETAPAS DA SEQUÊNCIA DIDÁTICA: ARTICULAÇÕES POSSÍVEIS
}

\section{THE EVALUATION MODALITIES AND THE STAGES OF THE DIDACTIC SEQUENCE: POSSIBLE JOINTS}

\author{
Marileuza Ascencio Miquelante* \\ Claudia Lopes Pontara** \\ Vera Lúcia Lopes Cristovão*** \\ Rosinalva Ordonia da Silva ${ }^{* * *}$
}

\section{RESUMO}

Partindo do pressuposto de que a avaliação é parte integrante do processo de ensino e aprendizagem e imprescindível na orientação das ações pedagógicas que visem à superação das dificuldades apresentadas pelos estudantes, este trabalho realiza uma análise sobre as possíveis articulações entre as modalidades da avaliação e as etapas do procedimento sequência didática (SD) (DOLZ, NOVERRAZ, SCHNEUWLY, 2004) e sobre como essa prática pode contribuir para o desenvolvimento das capacidades de linguagem. Com o intuito de analisar tal articulação, inicialmente, apresentamos o plano textual global de três SD implementadas em diferentes contextos, e, na sequência, classificamos as atividades. Para a análise das capacidades de linguagem, analisamos três versões de texto, de um dos estudantes do grupo do Ensino Superior. As análises revelam que o trabalho com a escrita, instrumento avaliativo foco deste estudo, ocorreu, em cada uma das SD, em três momentos distintos: primeira produção, revisão e reescrita da primeira produção e produção final, o que vai ao encontro da nossa defesa de que a SD possibilita colocar em prática as modalidades avaliativas e suas funções que são: diagnosticar, controlar e classificar (HAYDT, 2008, FURTOSO, 2008). Em relação às produções, as análises mostram que houve avanço quanto ao atendimento dos critérios das capacidades de linguagem, uma vez que, os apontamentos/ questionamentos feitos para orientar o estudante na retomada de aspectos já estudados em outros momentos foram atendidos promovendo o desenvolvimento de capacidades de linguagem.

Palavras-chave: avaliação; sequência didática; capacidades de linguagem

\section{ABSTRACT}

Based on the assumption that evaluation is an integral part of the teaching and learning process and indispensable in the orientation of pedagogical actions which aim at overcoming

\footnotetext{
* Universidade Estadual de Londrina, Londrina,PR. Brasil.mikelante@gmail.com

** Universidade Estadual de Londrina, Londrina, PR. Brasil. clpontara@gmail.com

*** Universidade Estadual de Londrina, Londrina, PR. Brasil. veraluciacristovao@gmail.com

**** Secretaria de Estado da Educação do Estado do Paraná, Curitiba, PR. Brasil. rosinalva. ordonia@gmail.com
} 
students' difficulties, this work carries out an analysis on the possible connections among the evaluation modalities and the stages of the procedure called didactic sequence (DS) (DOLZ, NOVERRAZ, SCHNEUWLY, 2004) and on how this practice may contribute to the development of language capacities. With the objective of analysing such joint, initially, a global overview of the three investigated DS in different contexts is presented, and, next, the activities are classified. In order to identify the language capacities, three versions of a text, written by one of the students from the tertiary level, were examined. The analysis reveal that the work with writing, evaluation tool focused in this study, was carried out, in each of the three DS, in three different moments: initial production, review and rewriting of the first production and final production, which meets our premise that the DS makes it possible for the evaluation modalities to be used and their functions that are: diagnose, control and classify (HAYDT, 2008, FURTOSO, 2008). Regarding the written productions, the analysis show that there was progress concerning the use of the criteria on the language capacities since the comments and feedback made to guide the student in the retrieval of aspects that had already been studied were considered fostering the development of language capacities.

Keywords: evaluation; didactic sequence; language capacities.

\section{INTRODUÇÃO}

Compreender a avaliação como parte integrante do processo de ensino e aprendizagem, imprescindível na orientação das ações pedagógicas que visem à superação das dificuldades apresentadas pelos estudantes, tem sido um tema recorrente nos estudos dos últimos anos (LUCKESI, 2012). No entanto, não é isso que observamos nas práticas educativas do contexto escolar brasileiro, independentemente do nível de ensino, uma vez que estudos acerca dessa temática, revelam que as escolas brasileiras praticam exames escolares, ao em vez de avaliação da aprendizagem (CHUEIRI, 2008; LUCKESI, 2003), inviabilizando que sejam consideradas as necessidades de um processo consistente para que seja possível um bom produto, ou seja, um resultado efetivo. Caso seja mantido o foco no processo ou no produto não obteremos os resultados esperados, caracterizando, portanto, a prevalência de um sobre o outro (LUCKESI, 2006).

Assim, cientes de que avaliar envolve coletar, analisar e sintetizar os dados (LUCKESI, 2002), e considerando que são muitas as inquietações no que tange à avaliação no contexto de ensino e aprendizagem de forma geral, há autores que vêm direcionando seus estudos para essa temática (HOFFMANN, 1998; LUCKESI, 2002, 2003, 2006; LEAL, 2010; SILVA, 2011; LIBÂNEO, 2012; SOUZA, 2012) com o intuito de contribuir para um melhor entendimento dos conceitos que subjazem a essa prática escolar.

Ao trazermos essa discussão para o campo de ensino e aprendizagem de Línguas, apresentamos o Interacionismo Sociodiscursivo (ISD) como nosso 
referencial teórico de base. Além disso, citamos Gonçalves e Nascimento (2010), que discutem sobre a avaliação e o ensino de língua materna. No tocante à Língua Inglesa (LI), temos Furtoso (2008), Scaramucci, $(2011$; 2014), Consolo (2004) e Cristóvão (2007), cujos estudos nos motivam a investigar a função da avaliação nesse contexto. Para tanto, traçamos como objetivo deste estudo realizar uma análise sobre as possíveis articulações entre as modalidades da avaliação e as etapas do procedimento sequência didática (SD) (DOLZ, NOVERRAZ, SCHNEUWLY, 2004) e sobre como essa prática pode contribuir para o desenvolvimento das capacidades de linguagem.

$\mathrm{Na}$ tentativa de atingir o objetivo proposto, dividimos nosso artigo em oito seções, incluindo a introdução. Na sequência, três seções são dedicadas à exposição de conceitos teóricos relativos ao Interacionismo Sociodiscursivo, ao procedimento Sequência Didática e às modalidades da avaliação. Na seção cinco, expomos nosso percurso metodológico, seguido de duas seções nas quais apresentamos e discutimos nossos resultados de análises. Finalmente, concluímos com algumas considerações.

\section{INTERACIONISMO SOCIODISCURSIVO: APRESENTANDO AS BASES FUNDAN- TES DESTA TEORIA}

O Interacionismo Sociodiscursivo (ISD) apresenta-se como um arcabouço teórico-metodológico que confere ao ensino de línguas um caráter de interação. De acordo com Bronckart (2006), o ISD não coaduna com a divisão das Ciências Humanas e Sociais, inscrevendo-se em um quadro teórico que deriva do Interacionismo Social, o qual teve sua expansão a partir dos anos 70/80, quando os textos de Vygotsky chegaram ao Brasil. Esse fato impulsionou novos estudos acerca das questões ligadas à linguagem, a exemplo do ISD, conforme colocado por Bronckart (2012, p. 13): "Nossas proposições teóricas derivam de uma psicologia da linguagem orientada pelos princípios epistemológicos do interacionismo social", o que significa o rompimento com as duas concepções de língua que antecederam os estudos interacionistas. A primeira, tida como expressão do pensamento, vê a língua ligada ao subjetivismo individualista, compreendendo-a como um ato psicológico individual, de caráter monológico. A segunda, definida como um meio de comunicação, concebe a língua como sistema abstrato, convencional e arbitrário, desconsiderando os valores ideológicos e a ligação entre o sistema da língua e a sua inscrição histórica (LEAL, 2011). Rompendo, portanto, com essas duas concepções, 
a partir dos estudos do Círculo Bakhtiniano, temos a linguagem concebida como um lugar de interação humana, no qual

A linguagem humana se apresenta, inicialmente, como uma produção interativa associadas às atividades sociais, sendo ela um instrumento pelo qual os interactantes, intencionalmente, emitem pretensões à validade relativas às propriedades do meio em que essa atividade se desenvolve. (BRONCKART, 2007, p.34)

Vygotsky, um dos referenciais de base do ISD, assevera: "A transmissão racional, intencional de experiências e de pensamentos a outrem exige um sistema mediador, que tem por protótipo a linguagem humana nascida da necessidade do intercâmbio durante o trabalho" (VYGOTSKY, 2002, p. 9). Desse modo, Bronckart (2012) enfatiza que a linguagem, sendo constitutiva das atividades sociais (gerais) do ser humano, apresenta-se como estritamente relacionada a essas. A atividade social, portanto, como fenômeno coletivo, demanda a atividade de linguagem, tendo os "gêneros como verdadeiras ferramentas semióticas complexas, que permitem que realizemos ações de linguagem, participando das atividades sociais de linguagem." (DOLZ; SCHNEUWLY, 2004)

Sendo assim, a escolha do gênero a ser empregado em uma dada situação de ação de linguagem constitui-se na mais geral das decisões por parte de um agente. Nesse sentido, Cristóvão (2007) discorre sobre a necessidade e importância de o indivíduo sócio-historicamente situado ampliar o conhecimento a respeito dos gêneros que circulam socialmente, esses sempre elaborados pelas gerações precedentes e (re)elaborados/transformados pela sociedade contemporânea:

[...] o domínio dos gêneros se constitui como instrumento que possibilita aos agentes produtores e leitores uma melhor relação com os textos, pois ao compreender como utilizar um texto pertencente a um determinado gênero, pressupõe-se que esses agentes poderão também transferir conhecimentos e agir com a linguagem de forma mais eficaz, mesmo diante de textos pertencentes a gêneros até então desconhecidos. (CRISTÓVÃO, 2007, p.3)

A partir de Schneuwly (2004), entendemos que, para os gêneros tornarem-se mediadores, transformadores da atividade, é necessário que sejam apropriados pelo sujeito, passando, dessa forma, do estatuto de artefato para o de instrumento. $\mathrm{O}$ artefato, segundo Schneuwly (2004, p. 21), é "o produto material existente fora do sujeito, materializando, por sua própria forma, as operações que tornam possíveis os fins aos quais o instrumento é destinado".

Nesse sentido, nos apoiamos no procedimento SD (DOLZ, NOVERRAZ, SCHNEUWLY, 2004), o qual propicia que o gênero de texto seja trazido para a sala de aula de modo a possibilitar agires linguageiros e não linguageiros (praxiológicos) 
com vistas a promover o desenvolvimento das capacidades de linguagem dos estudantes.

Em relação à definição de capacidades de linguagem, Cristóvão; Stutz (2011, p.20) esclarecem que:

São as operações necessárias para uma ação de linguagem que, na visão vigotskiana de instrumento, permitem transformar o conhecimento por meio de interações em situações de comunicação específicas em um processo contínuo de avaliação (de si, do outro e da própria situação).

Em outros termos, as capacidades de linguagem relacionam-se diretamente ao que o ISD denomina agir linguageiro, o qual, por sua vez, se articula a um agir praxiológico. O desenvolvimento dessas capacidades de linguagem, portanto, são primordiais para que o actante seja capaz de aprimorar o seu modo de agir com a linguagem, a fim de agir praxiologicamente de forma mais consciente e engajada.

As capacidades de linguagem são constituídas, segundo Dolz e Schneuwly (2004), por três tipos de operação: capacidades de ação (CA), capacidades discursivas (CD) e capacidades linguístico-discursivas (CLD).

Além dessas três capacidades de linguagem trazidas por Dolz e Schneuwly (2004), as quais já vêm sendo utilizadas em vários trabalhos de pesquisa, Cristóvão e Stutz (2011), argumentando a necessidade de haver uma categoria de análise que possibilite ao indivíduo construir sentidos mais gerais mediante representações e/ ou conhecimentos sobre as práticas sociais, apresentam uma nova capacidade de linguagem, a qual as autoras denominam "capacidades de significação (CS)".

A figura a seguir descreve, brevemente, cada uma das capacidades de linguagem citadas previamente: 


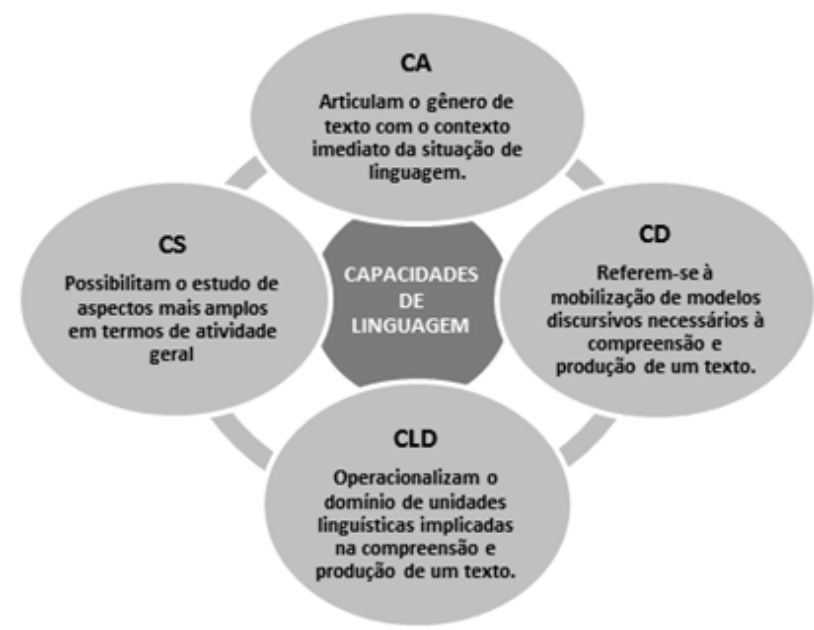

Figura 1. Descrição das Capacidades de Linguagem

Fonte: as autoras, com base em Dolz e Schneuwly (2004) e Cristóvão e Stutz (2011).

Apresentadas as quatro capacidades de linguagem, é necessário frisar que elas não são e não podem ser vistas como estanques, como fases/etapas de uma aula em que se propõe um trabalho a partir de gêneros de texto. Ao contrário, elas são complementares, são combinadas em busca de significações para o que se lê, se escreve, ouve ou fala. Nesse sentido, Cristóvão e Stutz (2011, p.23) argumentam que "Vale ressaltar que entendemos as capacidades como articuladas e atravessadas entre si colaborando para ser, estar, (inter)agir no mundo."

\section{SEQUÊNCIA DIDÁTICA: CONTEXTUALIZANDO ESSE PROCEDIMENTO}

Os autores genebrinos Dolz, Noverraz e Schneuwly (2004, p. 82) definem uma SD como "[...] um conjunto de atividades escolares organizadas, de maneira sistemática, em torno de um gênero textual oral ou escrito", cujo objetivo é ajudar o estudante a dominar um gênero de texto, possibilitando-lhe escrever e/ou falar de uma maneira apropriada em uma situação de comunicação. Os pesquisadores complementam afirmando que "As sequências didáticas servem, portanto, para dar acesso aos estudantes a práticas de linguagem novas ou dificilmente domináveis" (DOLZ; NOVERRAZ; SCHNEUWLY, 2004, p. 83).

Para tanto, a elaboração de uma SD deve partir de uma estrutura de base, conforme definido pelo grupo de pesquisadores de Genebra. Tal estrutura se 
configura em etapas assim denominadas: a) apresentação da situação; b) produção inicial; c) módulos necessários, de acordo com as necessidades de aprendizagem de uma determinada turma de estudantes e d) produção final.

A primeira etapa, denominada apresentação da situação, tem como objetivo situar o estudante no contexto de todo o trabalho que será desenvolvido. Nesse momento, podem ser apresentados os conteúdos que serão enfocados, os objetivos traçados, a proposta do agir que se espera concluir com a SD. Essa etapa é fundamental, pois é por meio dela que o estudante tomará conhecimento da finalidade, dos possíveis interlocutores, do suporte e do gênero de texto a ser produzido. Assim, a escrita assume, como afirma Bazerman (2000), uma função social, tornando-se um instrumento de participação capaz de transformar as cenas material e social da existência humana.

O segundo passo proposto é a "produção inicial", a qual tem por finalidade possibilitar que o estudante entre em contato, efetivamente, com textos do gênero enfocado na SD. Esse primeiro contato pode vir em forma de uma produção oral ou escrita, ou ainda por meio de atividades em que o estudante possa falar sobre o que já conhece a respeito do gênero e/ou tema propostos. $\mathrm{O}$ importante é que essa etapa forneça subsídios para que o professor possa (re)organizar as atividades seguintes, de acordo com as dificuldades e/ou possibilidades reais da turma.

Assim, uma primeira produção, considerando o caráter de processo que envolve o ensino via SD, constitui-se em um valioso momento de aprendizagem, o qual será retomado posteriormente. Para tanto, é importante não concebê-lo como um momento de avaliação somativa, por exemplo, cujo o objetivo é classificar os resultados do aprendizado do estudante. Além disso, em se tratando do ensino de LI, como o caso desta pesquisa, julgamos pertinente que a realização dessa produção inicial sirva como diagnóstico, para o aluno e para o professor observarem o que o estudante já sabe fazer e o que ainda apresenta como problema, com vistas a (re) definir a condução dessa etapa da própria SD.

Os módulos, em número variável, são organizados conforme as necessidades expressas diante da complexidade do gênero, bem como diante da proposta do agir. Constituem-se por várias atividades e exercícios, cujo objetivo é desenvolver as capacidades de linguagem dos estudantes mediante a apropriação mais efetiva do gênero em foco. Apropriação essa que se dá mediante o estudo, separadamente, dos diversos elementos constitutivos dos gêneros, dando origem a um processo de ensino e aprendizagem que vai do mais complexo ao mais simples, do todo (produção inicial) para as partes (módulos), voltando novamente ao todo (produção final). Ressaltamos que durante o desenvolvimento dos módulos o estudante tem a 
possibilidade de realizar a revisão e reescrita (DOLZ, GAGNON E DECÂNDIO, 2010; MENEGASSI, 2010; RUIZ, 2013; GASPARATTO, 2014), da sua produção inicial, a partir dos elementos estudados e dos apontamentos do professor.

$\mathrm{Na}$ última etapa da $\mathrm{SD}$, o estudante tem a possibilidade de pôr em prática tudo o que estudou módulo a módulo, aprimorando, assim, as versões anteriores de sua produção, de modo a apresentar a produção final, objeto da concretização da proposta do agir estabelecido no momento da apresentação da situação.

Apresentadas as etapas de uma SD para o oral e a escrita, importa ainda destacar que, apesar de haver uma organização previamente estabelecida para sua elaboração, isso não significa que essa ordem seja rígida e não aceite adaptações. Também não significa que, uma vez elaborada uma SD, ela deva ser compreendida como uma "camisa de força" que engessa o trabalho do professor a ponto de não permitir alterações, supressões, acréscimos. $\mathrm{Na}$ verdade, tendo sido uma SD elaborada para ser utilizada como material didático, passa-se para o nível interno da transposição didática ${ }^{1}$, o qual se realiza mediante condições presentes no contexto de sua implementação; condições essas que envolvem os aspectos físicos, materiais, a formação do professor, o nível real de conhecimento dos estudantes, dentre outros, conforme considerações de Dolz, Noverraz e Schneuwly (2004, p. 93):

[...] as sequências didáticas apresentam uma grande variedade de atividades que devem ser selecionadas, adaptadas e transformadas em função das necessidades dos estudantes, dos momentos escolhidos para o trabalho, da história didática do grupo e da complementaridade em relação a outras situações de aprendizagem da expressão, propostas fora do contexto das sequências didáticas.

Guardadas as diferenças dos contextos nos quais se originaram o procedimento SD e os contextos de realização deste estudo, acreditamos que os princípios teóricos subjacentes ao ensino de francês como língua materna podem também ser levados em consideração ao tratarmos do ensino de língua inglesa como língua estrangeira. Cristóvão e Stutz (2011), ao discorrerem sobre as semelhanças e especificidades de duas SD (sendo uma do contexto francófono para o ensino de francês como primeira língua e a outra do contexto brasileiro de ensino de língua inglesa), asseveram que as especificidades das atividades propostas em uma SD devem ser pensadas a partir das necessidades que emergem em cada contexto, bem

1 Termo criado pelo sociólogo francês Michel Verret, em 1975, tendo sido aprofundado por Yves Chevallard, matemático e educador francês, segundo o qual: "A transição do conhecimento considerado como uma ferramenta para ser colocada em uso, para o conhecimento como algo a ser ensinado e aprendido, é precisamente o que eu tenho chamado de transposição didática do conhecimento" (CHEVALLARD, 1989, p. 6 - tradução nossa). 
como a partir dos objetivos propostos para o ensino, seja ele de língua materna ou língua estrangeira.

Ao tratarem das semelhanças entre as duas SD, as autoras apresentam com pontos convergentes: a busca pelo aprimoramento das capacidades de linguagem em torno de gêneros de textos escolarizados; presença de macropropostas que visam a um texto com uma maior circulação e maior inserção social dos alunos; produção diagnóstica e produção final como propiciadoras de avaliação diagnóstica; presença de progressões alcançadas pelos alunos por meio da avaliação somativa; presença de informações extras e diversificadas com a intenção de dar subsídios aos alunos no desenvolvimento das atividades.

Outros estudiosos também têm se debruçado sobre o interesse de investigar a utilização do procedimento SD para o ensino de LI como língua estrangeira, dentre os quais citamos: Ferrarini (2009), Beato-Canato (2009), Denardi (2009), Rios-Registro (2013), Lanferdini (2012), Stutz (2012), Pontara (2015). Contudo, nenhum deles focou nas modalidades avaliativas. Dessa forma, passamos à discussão sobre avaliação e suas modalidades a fim de, posteriormente, estabelecermos as possíveis relações com o procedimento SD.

\section{AVALIAÇÃO: SUAS MODALIDADES E FUNÇÕES NO PROCESSO DE ENSINO APRENDIZAGEM}

Avaliar é prática constitutiva do trabalho pedagógico. Contudo, sua efetivação nem sempre se dá sem insegurança, sobressaltos e incertezas. Nosso trabalho se coloca nessa perspectiva: inicialmente, apresentar o construto teórico que subsidia nosso estudo a fim de aprofundar sua compreensão; em seguida, a partir de uma análise reflexiva acerca do procedimento metodológico aplicado, oferecer aos educadores alguns elementos que colaborem com seu referencial teórico sobre a avaliação e, por conseguinte, voltem sua atuação para um processo avaliativo qualitativo.

Bonesi e Souza (2006, p.146) asseguram que "a avaliação da aprendizagem não se dissocia do processo pedagógico como um todo, e seus diferentes campos de abordagem refletem a metodologia trabalhada"; desse modo, a escolha metodológica do procedimento SD para o processo de ensino e aprendizagem de uma LE requer que o professor compreenda as modalidades de avaliação, bem como suas funções nas diferentes etapas do trabalho desenvolvido. Furtoso (2008, p.147) também sugere essa coerência entre o foco de ensino e a avaliação ao destacar que " $[. .$. 
é preciso que nós, professores, sejamos capazes de buscar sempre esta coerência entre as concepções de aprendizagem/ensino/avaliação adotadas em nossa prática pedagógica".

Dessa forma, a prática avaliativa estará alinhavada ao que parece ser o objetivo central do processo avaliativo, ou seja, orientar o trabalho docente na perspectiva de favorecer a aprendizagem, situando o estudante no estágio de desenvolvimento em que se encontra, as mudanças que precisam ocorrer e o que pode ser atingido por ele.

Para ampliar a discussão acerca da ressignificação dessa prática pedagógica, apresentamos, a seguir, a distinção entre as modalidades de avaliação, bem como suas funções, analisando suas contribuições para o processo de ensino e aprendizagem.

\subsection{Avaliação dignóstica}

A necessidade de compreensão do papel da avaliação, de suas diferentes modalidades e a distinção de suas funções no processo de ensino e aprendizagem tem sido evidenciada em diversas pesquisas no campo da Educação (HADJI, 1993; HAYDT, 2008; FURTOSO, 2008; GONÇALVES; NASCIMENTO, 2012; SOUZA, 2012, entre outros).

De acordo com Hadji (1993, p.61), "podemos entender por função o papel característico de um elemento ou de um objecto no conjunto que está integrado", sendo assim, ao considerarmos a avaliação como elemento constitutivo do processo de ensino e aprendizagem, também reconhecemos que a mesma tem determinada função nesse processo. Para Haydt (2008), a avaliação apresenta três funções: diagnosticar, controlar e classificar. Ainda segundo essa autora, existem três modalidades de avaliação que estão vinculadas a essas funções: avaliação diagnóstica, avaliação formativa e avaliação somativa.

Bloom (1983, p.6) demonstra em seus estudos a preocupação em oferecer um quadro de referência sobre a tarefa de avaliar que possa colaborar com a "concepção segundo a qual a educação tem como função principal promover o desenvolvimento do indivíduo". Segundo ele, todas as formas de avaliação exigem a valoração, a determinação, a classificação de algum aspecto do comportamento do aluno. Entretanto, por ser efetuada antes do início de uma instrução, é a avaliação diagnóstica que permite a definição do ponto de partida do ensino.

Ainda segundo Bloom (1983), essa modalidade de avaliação tem a função de determinar se os estudantes possuem as habilidades para a consecução dos objetivos do conteúdo a ser estudado, determinar o seu nível de domínio prévio, classificá-los 
quanto às alternativas de ensino e, quando aplicada durante a instrução, determinar as causas subjacentes a repetidas deficiências na aprendizagem. Com esse diagnóstico, os professores têm elementos para identificar o conhecimento prévio dos alunos em relação aos conteúdos do curso ou série e, a partir daí, adequar os programas de ensino a fim de assegurar a superação das dificuldades evidenciadas.

Luckesi (2002, p.09) define a avaliação como "juízo de qualidade sobre dados relevantes para uma tomada de decisão". Para esse autor, a "avaliação diagnóstica pode ser uma saída para o modo autoritário de agir na prática educativa em avaliação". Diante disso, consideramos o diagnóstico como condição sine qua non do prognóstico, visto que só ele permite a intervenção futura baseada em dados da realidade.

\subsection{Avaliação formativa}

A concepção de avaliação formativa foi proposta por Scriven em 1967. Em seus estudos sobre a avaliação de currículos e programas, o autor defende que o objetivo da avaliação é sempre o mesmo: apreciar o valor, ou seja, julgar, formular juízos de valor. Contudo, para que o mesmo seja alcançado, é preciso que os avaliadores emitam julgamentos e que os dados obtidos pela avaliação sejam usados de forma construtiva para as mudanças necessárias, visando ao aperfeiçoamento programático. Nessa perspectiva, a avaliação formativa no contexto de ensino se caracteriza por ser processual, isto é, possibilita a interação entre o professor e o aluno ao longo do processo ensino e aprendizagem, uma vez que auxilia os envolvidos com informações acerca dos objetivos alcançados e os esforços necessários para desenvolver o que ainda não foi atingido.

Ampliando as pesquisas sobre avaliação no campo educacional, Bloom (1983, p. 9) postula que "a avaliação é a coleta sistemática de dados a fim de verificar se de fato certas mudanças estão ocorrendo no aprendiz, bem como verificar a quantidade ou grau de mudança ocorrido em cada aluno". Nesse caso, a avaliação formativa tem a função de fornecer um feedback informativo à medida que o aluno evolui, ou apresenta dificuldades nas etapas de estudo dos componentes considerados importantes na unidade de aprendizagem. A partir disso, a tarefa dos professores consiste em especificar as formas pelas quais os alunos serão modificados e tomar uma série de decisões (materiais a utilizar, métodos mais adequados, atividades desenvolvidas pelo aprendiz) para que a aprendizagem ocorra da forma desejada.

O desdobramento da tarefa de aprendizagem fornece os elementos para a construção dos testes ou procedimentos de avaliação formativa. Se estes instrumentos forem bem utilizados, 
podem fornecer a devida informação ao professor e aos alunos de quão adequadamente cada unidade está sendo aprendida, e também oferecer retro-informações sobre o que ainda é necessário para que a unidade seja dominada por cada aluno e pelo grupo como um todo. (BLOOM, 1983, p. 19)

Nesse sentido, Bloom (1983) considera a comunicação para os alunos de dados sobre seu progresso como a essência da avaliação formativa. Dessa forma, a avaliação fornece subsídios para as intervenções que ocorrem durante a formação do aluno visando aperfeiçoar o processo de ensino e aprendizagem. Além disso, esse autor demonstra sua oposição ao sistema de ensino que utiliza a avaliação de forma classificatória e assegura que, geralmente, as consequências negativas desse sistema para a aprendizagem ou para o bem-estar do aluno são desconsideradas pelos responsáveis pelo processo.

Sendo assim, compreendemos que a utilização dos dados da avaliação apenas para fins classificatórios pode afetar o potencial de instância mediadora da avaliação formativa, por conseguinte, reduzir a eficácia do processo de ensino e comprometer a aprendizagem efetiva dos estudantes.

Gonçalves e Nascimento (2012), em suas pesquisas sobre o ensino de língua materna com foco nas produções escritas dos estudantes, defendem a utilização da avaliação formativa como forma de regulação interativa da aprendizagem dos estudantes.

\subsection{Avaliação somativa}

Assim como a avaliação formativa, a concepção de avaliação somativa também foi proposta por Scriven. Para ele, a avaliação somativa assume o papel de uma avaliação final que serve para julgar o valor dos currículos inteiramente acabados e aperfeiçoados pelo uso do processo de avaliação em sua função primeira (formativa). Segundo Scriven (1967, p.6) não é preciso escolher entre essas duas modalidades avaliativas, mas sim, fazer o melhor uso de cada uma de suas funções. Isso pode justificar a sua coexistência com as demais modalidades avaliativas. As funções da avaliação são os propósitos a que serve, e estes podem variar muito: orientar projetos, classificar livros-textos, estabelecer relações com o público, etc. No caso das avaliações formativa e somativa, a primeira tem a função de apreciar as fases iniciais de um programa, enquanto a segunda deve julgar o valor de um programa após ter sido terminado independentemente de seus objetivos.

Bloom (1983. p.67) aponta que o objetivo da avaliação formativa é "determinar o grau em que o aprendiz dominou uma determinada tarefa de 
aprendizagem e detectar a parcela da tarefa que não foi dominada", enquanto a avaliação somativa tem por objetivo avaliar de modo geral em que grau os objetivos preestabelecidos foram atingidos. A frequência de aplicação e a posição ao longo do tempo do processo ensinar-aprender são outros fatores de diferenciação entre avaliação formativa e somativa da aprendizagem. Segundo o autor, os testes de natureza formativa são aplicados com maior frequência e durante o processo de ensino, já os testes de natureza somativa podem ser aplicados em vários momentos, todavia, tendem a ser aplicados somente ao final de um curso.

No contexto escolar, essa modalidade avaliativa, frequentemente, tem sido realizada ao final de um período, representado por uma unidade de ensino, capítulo, semestre ou ano letivo para fins de atribuição de notas, emissão de um certificado, avaliação do progresso ou eficiência de um currículo. As notas representadas por letras ou por números, assim como os conceitos, apresentam o resultado obtido pelo estudante ao término de um ciclo de ensino, classificando-o em termos de quantidade ou nível de aprendizagem atingido em relação aos demais alunos.

A avaliação somativa recebe diversas críticas por não permitir a regulação da aprendizagem, uma vez que apenas comunica resultados. No entanto, Furtoso (2008, p.142) afirma que "o mais importante e o que realmente vai fazer a diferença é o caminho percorrido para se chegar a este resultado". Corroborando a posição dessa autora, encontramos em Silva (2011) a defesa de que a aplicação da avaliação somativa é necessária para o sistema educacional como forma de retorno à sociedade dos resultados obtidos ao término do processo de ensino e aprendizagem. Além disso, a autora postula que quando o sistema avaliativo é pensado de forma integral as modalidades avaliativas têm funções importantes que se complementam.

Uma vez apresentadas as modalidades e funções da avaliação, passaremos a discorrer sobre a metodologia utilizada para a realização deste estudo.

\section{PERCURSO METODOLÓGICO}

Neste trabalho optamos pela abordagem qualitativo-interpretativa (SILVA e MENEZES, 2001; MARCONI; LAKATOS, 2003; MINAYO, 2001), a qual entende que há uma relação dinâmica entre o mundo objetivo e a subjetividade do sujeito, contribuindo sobremaneira para o processo de ensino e aprendizagem.

Sob essa perspectiva, a geração de dados foi realizada durante a implementação das SD produzidas pelas professoras pesquisadoras ${ }^{2}$ nos seus contextos de atuação. P1 era professora supervisora do PIBID/Língua Inglesa em um colégio da rede 
estadual de ensino do município de Campo Mourão-PR. A SD implementada em uma turma de $8^{\circ}$ ano do Ensino Fundamental foi produzida no período em que participou desse programa. As SD implementadas por P2 e P3 foram produzidas quando ambas atuavam na Educação Básica e participaram, entre os anos de 2010 e 2012, do projeto de produção de material didático para o Centro de Línguas Estrangeiras Modernas - CELEM, subsidiado pela Secretaria Estadual de Educação do Paraná, sob a orientação de professoras ${ }^{3}$ pertencentes a Instituições de Ensino Superior do país ${ }^{4}$. A implementação feita por P2 ocorreu quando atuava no CELEM de um colégio estadual na cidade de Apucarana-PR. No entanto, P3 fez a sua implementação no Ensino Superior, uma vez que, em 2012, passou a atuar como docente do Curso de Letras Português/Inglês de uma Universidade Pública do norte paranaense.

Com o intuito de explicitar que a articulação entre as modalidades de avaliação e as etapas da SD pode acontecer em qualquer nível de ensino, apresentamos, inicialmente, o plano textual global - PTG das três SD implementadas, bem como destacamos os comandos das propostas de escrita em cada uma delas.

Entretanto, optamos por centrar nosso estudo naquela implementada no Ensino Superior, devido à lacuna de estudos em relação à avaliação, nesse nível de ensino, ser ainda maior (SOUZA, 2012).

No contexto escolhido, os participantes da pesquisa eram acadêmicos de um terceiro ano de Letras - Licenciatura Dupla, de uma universidade pública do estado do Paraná. A grande maioria pertencia à classe trabalhadora, ou seja, além de pais trabalhadores, eles (os estudantes) também já estavam inseridos no mundo do trabalho.

O texto, em três versões, de um dos estudantes do grupo, foi selecionado para este estudo, devido ao fato de que o seu autor foi o primeiro a cumprir todas as etapas da produção escrita.

Utilizamos como fio condutor para a análise das diferentes versões da produção escrita, os objetivos de cada modalidade de avaliação, bem como as capacidades de linguagem mobilizadas pelo estudante durante o processo de produção escrita. Analisamos também os comandos das atividades de escrita, outras atividades da $\mathrm{SD}$ e os apontamentos de $\mathrm{P}$, a fim de identificarmos se favorecem a

2 As professoras pesquisadoras serão denominadas $\mathrm{P} 1$, P2 e P3, sendo $\mathrm{P} 1$ - a professora do $8^{\circ}$ ano; $\mathrm{P} 2$ - a professora do CELEM e P3 a professora do Ensino Superior.

3 P4 foi a orientadora do projeto de produção de material didático e é coautora do artigo.

4 Importante ressaltar que a publicação desse material não aconteceu por questões políticas. Houve troca de governador, alterando as políticas de investimento no campo educacional. 
efetivação das funções de cada modalidade avaliativa, assim como a mobilização das capacidades de linguagem.

Para investigarmos as capacidades de linguagem mobilizadas pelo estudante, nas diferentes versões do texto, utilizamos os critérios propostos por Cristóvão et.al. (2010) e Cristóvão e Stutz (2011), a saber:

Quadro 1. Critérios para análise das capacidades de linguagem

\begin{tabular}{|c|c|c|}
\hline $\begin{array}{l}\text { CAPACIDADES } \\
\text { DE } \\
\text { LINGUAGEM }\end{array}$ & & CRITÉRIOS PARA ANÁLISE \\
\hline \multirow{4}{*}{$\begin{array}{l}\text { CAPACIDADES } \\
\text { DE AÇÃO }\end{array}$} & $1 \mathrm{CA}$ & $\begin{array}{l}\text { Realizar inferências sobre: quem escreve o texto, para quem ele é } \\
\text { dirigido, sobre qual assunto, quando o texto foi produzido, para } \\
\text { que objetivo }\end{array}$ \\
\hline & 2CA & $\begin{array}{l}\text { Avaliar a adequação de um texto à situação na qual se processa a } \\
\text { comunicação }\end{array}$ \\
\hline & $3 \mathrm{CA}$ & $\begin{array}{l}\text { Levar em conta propriedades linguageiras na sua relação com } \\
\text { aspectos sociais e/ou culturais }\end{array}$ \\
\hline & $4 \mathrm{CA}$ & $\begin{array}{l}\text { Mobilizar conhecimentos de mundo para compreensão e/ou } \\
\text { produção de um texto }\end{array}$ \\
\hline \multirow{4}{*}{$\begin{array}{l}\text { CAPACIDADES } \\
\text { DISCURSIVAS }\end{array}$} & $1 \mathrm{CD}$ & $\begin{array}{l}\text { Reconhecer a organização do texto como: layout, linguagem não } \\
\text { verbal (fotos, gráficos, títulos, formato do texto, localização de } \\
\text { informação específica no texto) etc. }\end{array}$ \\
\hline & $2 \mathrm{CD}$ & $\begin{array}{l}\text { Mobilizar mundos discursivos para engendrar o planejamento geral } \\
\text { do conteúdo temático }\end{array}$ \\
\hline & $3 \mathrm{CD}$ & Entender a função da organização do conteúdo naquele texto \\
\hline & $4 \mathrm{CD}$ & $\begin{array}{l}\text { Perceber a diferença entre formas de organização diversas dos } \\
\text { conteúdos mobilizados }\end{array}$ \\
\hline \multirow{4}{*}{$\begin{array}{l}\text { CAPACIDADES } \\
\text { LINGUÍSTICO- } \\
\text { DISCURSIVAS }\end{array}$} & $1 \mathrm{CDL}$ & $\begin{array}{l}\text { Compreender os elementos que operam na construção de textos, } \\
\text { parágrafos, orações }\end{array}$ \\
\hline & $2 \mathrm{CDL}$ & $\begin{array}{l}\text { Dominar operações que contribuem para a coerência de um texto } \\
\text { (organizadores textuais, por exemplo) }\end{array}$ \\
\hline & $3 \mathrm{CDL}$ & $\begin{array}{l}\text { Dominar operações que colaboram para a coesão nominal de um } \\
\text { texto (anáforas, por exemplo) }\end{array}$ \\
\hline & $4 \mathrm{CDL}$ & $\begin{array}{l}\text { Dominar operações que cooperam para a coesão verbal de um texto } \\
\text { (tempo verbal, por exemplo) }\end{array}$ \\
\hline
\end{tabular}




\begin{tabular}{|c|c|c|}
\hline \multirow{7}{*}{$\begin{array}{l}\text { CAPACIDADES } \\
\text { LINGUÍSTICO- } \\
\text { DISCURSIVAS }\end{array}$} & $5 \mathrm{CDL}$ & $\begin{array}{l}\text { Expandir o vocabulário para permitir melhor compreensão e } \\
\text { produção de textos }\end{array}$ \\
\hline & $6 \mathrm{CDL}$ & $\begin{array}{l}\text { Compreender e produzir unidades linguísticas adequadas a sintaxe, } \\
\text { morfologia, fonética, fonologia e semântica da língua }\end{array}$ \\
\hline & $7 \mathrm{CDL}$ & Tomar consciência das diferentes vozes que constroem o texto \\
\hline & $8 \mathrm{CDL}$ & $\begin{array}{l}\text { Perceber as escolhas lexicais para tratar de determinado conteúdo } \\
\text { temático }\end{array}$ \\
\hline & 9CDL & Reconhecer a mobilização (ou não)em um texto \\
\hline & $10 \mathrm{CDL}$ & $\begin{array}{l}\text { Identificar a relação entre os enunciados, as frases e os parágrafos de } \\
\text { um texto, entre outras muitas operações que poderiam ser citadas }\end{array}$ \\
\hline & $11 \mathrm{CDL}$ & $\begin{array}{l}\text { Identificar as características do texto que podem fazer o autor } \\
\text { parecer mais distante ou mais próximo do leitor }\end{array}$ \\
\hline \multirow{8}{*}{$\begin{array}{l}\text { CAPACIDADES } \\
\text { DE } \\
\text { SIGNIFICAÇÃO }\end{array}$} & $1 \mathrm{CS}$ & $\begin{array}{l}\text { Compreender a relação entre textos e a forma de ser, pensar, agir, e } \\
\text { sentir de quem os produz }\end{array}$ \\
\hline & $2 \mathrm{CS}$ & Construir mapas semânticos \\
\hline & $3 \mathrm{CS}$ & Engajar-se em atividades de linguagem \\
\hline & $4 \mathrm{CS}$ & Compreender conjuntos de pré-construidos coletivos \\
\hline & $5 \mathrm{CS}$ & Relacionar os aspectos macro com sua realidade \\
\hline & 6CS & $\begin{array}{l}\text { Compreender as imbricações entre atividades praxiológicas e de } \\
\text { linguagem }\end{array}$ \\
\hline & 7CS & (Re)conhecer a sócio-história do gênero \\
\hline & $8 \mathrm{CS}$ & Posicionar-se sobre relações textos-contextos \\
\hline
\end{tabular}

Fonte: as autoras, com base em Cristóvão et.al. (2010) e Cristóvão e Stutz (2011)

Passamos, a seguir, para a discussão dos dados, conforme já especificado anteriormente.

\section{AS MODALIDADES AVALIATIVAS E AS ETAPAS DA SD: POSSÍVEIS ARTICU- LAÇÕES}

Para ilustrar a nossa defesa de que a SD possibilita aos envolvidos no processo de ensino e aprendizagem colocar em prática as diferentes modalidades avaliativas - diagnóstica, formativa e somativa (SCRIVEN, 1967; BLOOM, 1983; HAYDT, 2008; FURTOSO, 2008), por meio da compreensão e da produção de gêneros orais ou escritos, apoiamo-nos na concepção de avaliação entendida como processo dinâmico, capaz de promover a ação e a reflexão (HOFFMANN, 1998), a partir dos objetivos, instrumentos e critérios de avaliação, estabelecidos em cada SD. 
O corpus de análise desse estudo parte da estrutura de base de uma SD constituída pelas seguintes etapas: "apresentação da situação, produção inicial, módulo I, módulo II, módulo $\mathrm{N}$ e produção final" (DOLZ; NOVERRAZ; SCHNEUWLY, 2004) e consta de três SD, a saber: 1) Bilhetes: aprendendo como escrever e se comunicar ${ }^{5}$, implementada em uma turma de $8^{\circ}$ ano do Ensino Fundamental, de uma escola pública do Estado do Paraná; 2) Histórias em quadrinhos e charges: um modo engraçado de ver a vida real - Compreendendo o implícito por meio dos quadrinhos ${ }^{6}$, implementada em uma turma de $1^{\circ}$ ano do CELEM; 3) Poesia: lendo além das palavras ${ }^{7}$, implementada no $3^{\circ}$ ano do Curso de Letras - Licenciatura Dupla de uma universidade pública do Estado do Paraná.

Inicialmente, apresentamos o PTG das três SD implementadas em turmas de níveis de ensino diferentes.

A SD implementada por P1 está organizada em 12 páginas e tem como gênero central o bilhete, cujo estudo se volta para um agir praxiológico dos estudantes com vistas ao seu uso, em diferentes momentos e espaços sociais. Essa SD é composta por 21 atividades, as quais se subdividem em 26 questões $^{8}$, envolvendo a compreensão e produção escrita e a compreensão e produção oral. No quadro a seguir, apresentamos o PTG da referida SD.

5 Short notes: learning how to write and communicate.

6 Comics and cartoons: a funny way of seeing the real life - Comprehending the implicit through comics.

7 Poetry: Reading beyond the words.

8 Chamamos de atividades os enunciados que indicam um exercício mais amplo; e de questões, as subdivisões encontradas nessas atividades, quando elas nos remetem a diferentes capacidades de linguagem. 


\section{Quadro 2. PTG da SD Short notes: learning how to write and communicate}

\begin{tabular}{|c|c|c|c|}
\hline & \multicolumn{3}{|c|}{\begin{tabular}{|l|} 
OBJETIVOS DA UNIDADE \\
- Estudar as principais características de SHORT NOTES \\
- Desenvolver as capacidades de linguagem necessárias \\
para ler e produzir SHORT NOTES \\
- Refletir sobre a função social do gênero SHORT NOTES
\end{tabular}} \\
\hline & ESTRUTURA DA SD & RTIVIDRDES & RECURSOS \\
\hline $\begin{array}{l}\text { Apresentaçăo } \\
\text { situação }\end{array}$ & $\begin{array}{l}\text { Project of communication: } \\
\text { Introduction and presentation }\end{array}$ & $\begin{array}{l}\text { Leitura de imagens - Diagnóstico do } \\
\text { conhecimento prévio do estudante } \\
\text { sobre o gênero a ser estudado }\end{array}$ & Slides PowerPoint \\
\hline Módulo & $\begin{array}{l}\text { Getting in touch with the } \\
\text { textual genre. }\end{array}$ & $\begin{array}{l}\text { Leitura de diferentes textos e estudo sobre } \\
\text { suas funções e elementos constitutivos do } \\
\text { Gênero Bilhete. }\end{array}$ & $\begin{array}{l}\text { Material impresso e } \\
\text { visual. }\end{array}$ \\
\hline $\begin{array}{l}\text { Produção } \\
\text { Inicial }\end{array}$ & First production. & Produção inicial escrita. & $\begin{array}{l}\text { Material impresso e } \\
\text { manuscrito. }\end{array}$ \\
\hline Módulo & $\begin{array}{l}\text { Studying the main elements } \\
\text { of Short Notes. }\end{array}$ & $\begin{array}{l}\text { Compreensão escrita e estudo dos } \\
\text { elementos que compõem um bilhete. }\end{array}$ & Material impresso. \\
\hline Reescrita & $\begin{array}{l}\text { Rewriting the first } \\
\text { production. }\end{array}$ & Revisão e reescrita da produção inicial. & $\begin{array}{l}\text { Material impresso e } \\
\text { manuscrito. }\end{array}$ \\
\hline \& & $\begin{array}{l}\text { Studying some elements of } \\
\text { short notes: modal verbs. }\end{array}$ & $\begin{array}{l}\text { Estudo dos elementos linguístico- } \\
\text { discursivos. }\end{array}$ & Material impresso. \\
\hline$\frac{\bar{z}}{\bar{D}}$ & $\begin{array}{l}\text { Studying a Short Note from } \\
\text { the movie The Little } \\
\text { Rascals. }\end{array}$ & $\begin{array}{c}\text { Compreensão oral do excerto do filme The } \\
\text { Little Rascals. } \\
\text { Compreensão escrita das duas versões do } \\
\text { bilnete que aparecem no excerto do filme }\end{array}$ & $\begin{array}{l}\text { Vídeo e material } \\
\text { impresso. }\end{array}$ \\
\hline $\begin{array}{l}\text { Produção } \\
\text { Final }\end{array}$ & Final production. & $\begin{array}{l}\text { Revisão e reescrita da segunda versão } \\
\text { da produção inicial do bilhete, conforme } \\
\text { apontamentos do professor e as } \\
\text { orientações da lista de constatação. }\end{array}$ & $\begin{array}{l}\text { Material impresso e } \\
\text { manuscrito. }\end{array}$ \\
\hline
\end{tabular}

Fonte: as autoras com base na SD.

O quadro mostra que, embora, tivéssemos uma SD curta, ainda assim houve a preocupação em realizar o processo de escrita em três etapas, evidenciando que as modalidades avaliativas se fizeram presentes, pois temos a Primeira produção que corresponde à avaliação diagnóstica; Reescrita da primeira produção ${ }^{10}$, que relacionamos à avaliação formativa e a Produção Final ${ }^{11}$, compreendida por nós como propiciadora das modalidades de avalição formativa e somativa. Além disso, P1 também fez uso de outras atividades avaliativas, tais como: prova objetiva, envolvendo itens de resposta curta; lacunas e múltipla escolha (HAYDT, 2008).

A SD implementada por P2 está organizada em 21 páginas, intitulada Comics and cartoons: a funny way of seeing the real life - Comprehending the implicit through comics.

9 First production.

10 Rewriting the first production.

11 Final production 
Explora os gêneros de texto histórias em quadrinhos, tiras e charges ${ }^{12}$, os quais estão voltados para um agir dos estudantes visando à realização de uma campanha de trabalho voluntário com enfoque local (escolar ou da comunidade). A SD é composta de 68 atividades, as quais se subdividem em 117 questões.

Segue o Quadro 3 com o PTG da referida SD:

\section{Quadro 3. PTG da SD Comics and cartoons: a funny way of seeing the real life - Comprehen- ding the implicit through comics}

\begin{tabular}{|c|c|c|c|}
\hline & \multicolumn{3}{|c|}{$\begin{array}{l}\text { OBJETIVOS DA UNIDADE } \\
\text { - Reconhecer as características dos gêneros textuais comics, comic strip e editorial cartoon. } \\
\text { - Ler e compreender textos dos gêneros escolhidos para unidade. } \\
\text { - Discutir sobre a temática do voluntariado. } \\
\text { - Produzir Comics sobre voluntariado, visando a uma campanha de enfoque local escolar } \\
\text { ou de sua comunidade. }\end{array}$} \\
\hline & ESTRUTURA DA SD & TIPO DE ATIVIDADE & RECURSOS \\
\hline \multirow{2}{*}{$\begin{array}{l}\text { APRESENTAÇÃo } \\
\text { DA } \\
\text { SITUAÇÃO }\end{array}$} & First Page & Apresentação do agir linguageiro e praxiológico & Material Impresso \\
\hline & Self-assessment & $\begin{array}{l}\text { Diagnóstico do conhecimento prévio do estudante } \\
\text { sobre o gênero a ser estudado. }\end{array}$ & Material Impresso \\
\hline \multirow{7}{*}{ 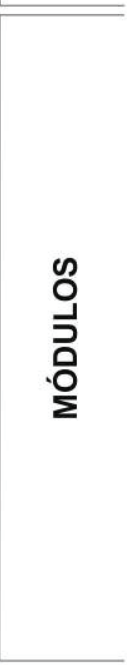 } & $\begin{array}{l}\text { Finding out about the } \\
\text { communicative context. }\end{array}$ & $\begin{array}{l}\text { Compreensão oral e escrita do Animated Cartoon } \\
\text { (Garfield Quickie - Slace to the passions) } \\
\text { Leitura e compreensão escrita de uma curta } \\
\text { biografia sobre o autor de Garfield. }\end{array}$ & $\begin{array}{l}\text { Video e Material } \\
\text { Impresso }\end{array}$ \\
\hline & $\begin{array}{l}\text { Reflecting about the } \\
\text { context and content. }\end{array}$ & $\begin{array}{l}\text { Comic strip (Garfield Quickie - Slave to the passions) } \\
\text { Leitura, compreensão e análise de alguns } \\
\text { elementos do contexto discursivo. }\end{array}$ & Material Impresso \\
\hline & $\begin{array}{l}\text { Reflecting about } \\
\text { the genre. }\end{array}$ & $\begin{array}{l}\text { Texto informativo sobre o Gênero Comic Strip. } \\
\text { Atividades de leitura, compreensão, ampliação } \\
\text { de vocabulário. }\end{array}$ & Material Impresso \\
\hline & Fun and Games & Compreensão oral (Listening) & $\begin{array}{l}\text { Cartazes com } \\
\text { imagens dos } \\
\text { personagens }\end{array}$ \\
\hline & $\begin{array}{l}\text { Reflecting about } \\
\text { the content }\end{array}$ & $\begin{array}{l}\text { Compreensão oral e escrita do animated cartoon } \\
\text { (Garfield in a Big Date) }\end{array}$ & $\begin{array}{l}\text { Video e Material } \\
\text { Impresso }\end{array}$ \\
\hline & $\begin{array}{l}\text { Reflecting about } \\
\text { the text organization }\end{array}$ & $\begin{array}{l}\text { Comics (Monicas's gang) - Leitura e compreensão, } \\
\text { análise de elementos discursivos } \\
\text { e linguísticos-discursivos. }\end{array}$ & Material Impresso \\
\hline & $\begin{array}{l}\text { Reflecting about } \\
\text { the language }\end{array}$ & $\begin{array}{l}\text { Compreensão oral e escrita do animated cartoon } \\
\text { (Onomatopeia), texto informativo sobre onomatopeia } \\
\text { Atividades envolvendo elementos discursivos } \\
\text { e linguistico-discursivos. }\end{array}$ & $\begin{array}{l}\text { Video e Material } \\
\text { Impresso }\end{array}$ \\
\hline $\begin{array}{l}\text { PRODUÇÃo } \\
\text { INICIALII }\end{array}$ & $\begin{array}{l}\text { Working on your text } \\
\text { production }\end{array}$ & $\begin{array}{l}\text { Primeira atividade de produção escrita - } \\
\text { com tema livre }\end{array}$ & Internet \\
\hline 哭 & $\begin{array}{l}\text { Reflecting about } \\
\text { the content }\end{array}$ & $\begin{array}{l}\text { Comics (Monica's gang), texto informativo sobre } \\
\text { trabalho voluntário, comic strip (voluntariado) - leitura } \\
\text { e compreensão escrita, atividades envolvendo } \\
\text { elementos discursivos e linguístico-discursivos. }\end{array}$ & Material Impresso \\
\hline $\begin{array}{l}\text { PRODUÇĂO } \\
\text { INICIALL II }\end{array}$ & $\begin{array}{l}\text { Working on your } \\
\text { text production }\end{array}$ & Produção escrita - envolvendo o tema voluntariado. & Material Impresso \\
\hline
\end{tabular}

12 Comics, comic strips and political cartoons. 


\begin{tabular}{|c|c|c|c|}
\hline \multirow{4}{*}{$\begin{array}{l}\text { め } \\
\text { 곡 } \\
\text { 을 }\end{array}$} & $\begin{array}{l}\text { Find out about the } \\
\text { communicative context }\end{array}$ & $\begin{array}{l}\text { Political Cartoon (tema biodiesel) - leitura e } \\
\text { compreensão escrita. }\end{array}$ & Material Impresso \\
\hline & $\begin{array}{l}\text { Reflecting about } \\
\text { the context }\end{array}$ & $\begin{array}{l}\text { Texto informativo (sobre o tema biodiesel e sobre a } \\
\text { forte de publicação dos Political Cartoons sobre o } \\
\text { biodiesel), leitura e compreensão escrita. }\end{array}$ & Material Impresso \\
\hline & $\begin{array}{l}\text { Reflecting about } \\
\text { the genre }\end{array}$ & $\begin{array}{l}\text { Texto explicativo (gênero textual Political Cartoon), } \\
\text { estudo de elementos discursivos do gênero. }\end{array}$ & Material Impresso \\
\hline & $\begin{array}{l}\text { Reflecting about the } \\
\text { content and language }\end{array}$ & $\begin{array}{l}\text { Comic Strips (envolvendo o tema voluntariado e } \\
\text { figuras de linguagem), leitura e compreensão escrita. } \\
\text { Estudo de elementos discursivos e } \\
\text { linguístico-discursivos. }\end{array}$ & Material Impresso \\
\hline \multirow[t]{2}{*}{ REESCRITA } & $\begin{array}{l}\text { Working on your final } \\
\text { text production - } \\
\text { evaluation and } \\
\text { self-check }\end{array}$ & Produção escrita - revisão e reescrita. & Material Impresso \\
\hline & Critical thinking & Reflexão crítica acerca da função social do gênero. & Material Impresso \\
\hline
\end{tabular}

Fonte: as autoras com base na SD.

O Quadro 3 evidencia a presença de uma SD mais longa e complexa, tendo em vista o nível de ensino ao qual se destina e também as próprias características ${ }^{13}$ dos gêneros em estudo. As orientações e explicações trazidas na Página Inicial, bem como a realização da Autoavaliação ${ }^{14}$, têm o intuito de contextualizar o processo de ensino que está para ter início, de modo que o aluno tenha ciência do que irá estudar e compreenda o porquê desse estudo. A autoavaliação, mais especificamente, ao mesmo tempo em que apresenta de forma indireta os conteúdos propostos na SD, também possibilita que o aluno se autoavalie. Consideramos, portanto, que, já nas atividades presentes nas duas páginas iniciais da $\mathrm{SD}$, tenha início um processo de avaliação numa dimensão discursiva (SUASSUNA, 2007), compreendendo, em nosso entender, tanto a dimensão diagnóstica, quanto a formativa.

Na sequência, os módulos tratam das especificidades dos gêneros em estudo, bem como da temática a ser desenvolvida na produção escrita. As atividades constantes nesses momentos colaboram para a efetivação de uma avaliação formativa, visto que apresentam como função a possibilidade de fornecer informações, tanto ao professor quanto ao aluno, acerca das dificuldades apresentadas, afinal:

[...] o processo avaliativo não se restringe a procedimentos formais de avaliação - teste, correção pelo professor, mensuração de resultados, proposição de ajustes - pelo contrário, permeia toda a dinâmica educativa. Deste modo, o professor pode perceber necessidades de ajustes enquanto observa o andamento das atividades em sala. [...] (RIBEIRO, 2011, p. 74)

13 Pontara $(2015$, p.98), ao apresentar um estudo sobre os gêneros dos quadrinhos, afirma: "[...] embora os gêneros dos quadrinhos sejam visualmente identificáveis, sem grandes dificuldades, entendemos que também são carregados de grande complexidade discursiva, demandando um estudo sistematizado, tanto por parte do produtor que se dispõe a produzir tais textos, quando do receptor que irá ler e interagir com eles."

14 Self-assessment 
Além disso, a atividade de escrita aparece em três momentos: a primeira Trabalhando em sua produção de texto ${ }^{15}$, sendo uma produção inicial de tema livre, do gênero dos quadrinhos, podendo propiciar, ao professor e também ao aluno, que percebam suas dificuldades e/ou conhecimentos já presentes relacionados às características discursivas, bem como às linguístico-discursivas do texto. $\mathrm{O}$ segundo momento, Trabalhando em sua produção de texto ${ }^{16}$, continua com o mesmo gênero, mas já define o tema, o suporte, o objetivo do texto; e o terceiro momento Trabalhando em sua produção final do texto ${ }^{17}-$ em que se dá a reescrita do texto produzido no segundo momento.

Dessa forma vemos, nesse trabalho de escrita, a possibilidade de ocorrerem as três modalidades de avaliação: diagnóstica, formativa e somativa, as quais deflagram um processo avaliativo inserido numa dimensão discursiva, indo ao encontro da concepção de linguagem assumida neste trabalho.

A SD implementada por P3 está organizada em 21 páginas, explora os gêneros poema e comentário, cujo estudo se volta para um agir praxiológico dos estudantes com vistas à produção de um comentário sobre o poema Caminho não trilhado $^{18}$ a ser publicado no site < bttp://www.poembunter.com/poem/the-road-not-taken/>. Esta SD é composta por 85 atividades, as quais apresentam uma subdivisão de mais 57 questões.

O Quadro 4 apresenta o PTG da referida SD:

15 Working on your text production. 16 Working on your text production. 17 Working on your final text production. 18 The road not taken. 


\section{Quadro 4. PTG da SD Poetry: Reading beyond the words}

\begin{tabular}{|c|c|c|}
\hline & \multicolumn{2}{|c|}{$\begin{array}{l}\text { OBJETIVOS DA UNIDADE } \\
\text { - Desenvolver a capacidade leitora.. } \\
\text { - Propiciar o reconhecimento dos elementos que diferenciam um texto poéticı } \\
\text { - Reconhecer, identificar e compreender o uso da linguagem figurada pelos p } \\
\text { sua importância para a construção de sentidos do texto. } \\
\text { - Reconhecer os elementos propiciadores da intertextualidade } \\
\text { - Propiciar o contato com diferentes autores com vistas à leitura e análise da } \\
\text { poemas lidos. } \\
\text { - Oportunizar o acesso a comentários feitos sobre poemas, bem como produz } \\
\text { publicação online. } \\
\text { - Analisar a temática dos poemas lidos e relacioná-la a sua própria experiênc }\end{array}$} \\
\hline & ESTRUTURA DA SD & TIPO DE ATIVIDADE \\
\hline \multirow{2}{*}{$\begin{array}{l}\text { APRESENTAÇĀo } \\
\text { DA } \\
\text { SITUAÇĀO }\end{array}$} & First Page & Apresentação do agir linguageiro e praxiológico \\
\hline & Self-assessment & $\begin{array}{l}\text { Diagnóstico do conhecimento prévio do estudante } \\
\text { sobre o gênero a ser estudado. }\end{array}$ \\
\hline \multirow{2}{*}{$\begin{array}{l}\text { @ } \\
\text { 곡 } \\
\text { 일 }\end{array}$} & $\begin{array}{l}\text { Finding out about the } \\
\text { communicative context. }\end{array}$ & $\begin{array}{l}\text { Leitura de texto imagético e discussão } \\
\text { acerca de alguns dos elementos do contexto } \\
\text { discursivo. }\end{array}$ \\
\hline & $\begin{array}{l}\text { Reflecting about the } \\
\text { genre and the context } \\
\text { (Poem). }\end{array}$ & $\begin{array}{l}\text { Ccompreensão oral de excerto de filme e da } \\
\text { leitura expressiva de um poema. Estudo do } \\
\text { contexto discursivo do poema em análise.. }\end{array}$ \\
\hline \multirow[t]{4}{*}{$\begin{array}{l}\text { PRODUÇÃO } \\
\text { INCIAL }\end{array}$} & $\begin{array}{l}\text { Working on your text } \\
\text { production.. }\end{array}$ & Produção escrita \\
\hline & Fun \& Games & Compreensão escrita (Reading) \\
\hline & $\begin{array}{l}\text { Reflecting about } \\
\text { the genre (poem) }\end{array}$ & $\begin{array}{l}\text { Estudo dos elementos que compõem um } \\
\text { poema (capacidade discursiva). }\end{array}$ \\
\hline & $\begin{array}{l}\text { Reflecting about the } \\
\text { context and content. }\end{array}$ & $\begin{array}{l}\text { Compreensão escrita e estudo dos } \\
\text { elementos discursivos. }\end{array}$ \\
\hline \multirow{6}{*}{$\begin{array}{l}0 \\
0 \\
0 \\
0 \\
0\end{array}$} & $\begin{array}{l}\text { Reflecting about } \\
\text { the language }\end{array}$ & $\begin{array}{l}\text { Estudo dos elementos linguístico- } \\
\text { discursivos. }\end{array}$ \\
\hline & $\begin{array}{l}\text { Working at the } \\
\text { INFO LAB - } \\
\text { Interviewing friends. }\end{array}$ & Compreensão e produção oral. \\
\hline & $\begin{array}{l}\text { Reflecting about the } \\
\text { genre and context } \\
\text { (Comment). }\end{array}$ & Estudo dos elementos discursivos. \\
\hline & $\begin{array}{l}\text { Reflecting about the } \\
\text { context and content. }\end{array}$ & $\begin{array}{l}\text { Compreensão escrita e estudo dos } \\
\text { elementos discursivos. }\end{array}$ \\
\hline & $\begin{array}{l}\text { Reflecting about } \\
\text { the language }\end{array}$ & $\begin{array}{l}\text { Estudo dos elementos linguístico- } \\
\text { discursivos. }\end{array}$ \\
\hline & Critical thinking & $\begin{array}{l}\text { Compreensão escrita e reflexão crítica } \\
\text { acerca da temática e do gênero. }\end{array}$ \\
\hline REESCRITA & $\begin{array}{l}\text { Working on your text } \\
\text { production.. }\end{array}$ & Produção escrita - revisão e reescrita. \\
\hline
\end{tabular}

Fonte: as autoras, com base na SD. 
Assim como o PTG da SD Comics and cartoons: a funny way of seeing the real life Comprehending the implicit through comics, o Quadro 3 apresenta uma SD mais longa e complexa. Em primeiro lugar, por ser a décima segunda unidade de um cronograma de curso distribuído em dezesseis SD e, em segundo, por ter sido utilizada em um contexto de formação inicial, com uma turma de terceiro ano de Letras Português/ Inglês e suas Literaturas. Desde as primeiras orientações e atividades, há evidências de que o estudante é chamado a fazer parte do processo de ensino e aprendizagem. A contextualização, os objetivos, o quadro sumário e a autoavaliação ${ }^{19}$ corroboram com o apontado.

Nesta unidade você terá a
oportunidade de aprender
sobre os gêneros de textos
poema e comentário, tanto
orais quanto escritos, os
quais contribuirão para
o desenvolvimento das
capacidades necessárias
para a recepção e produção
desses gêneros nas
diferentes esferas sociais de
circulação.

O trabalho com essa unidade tem como objetivos:

- desenvolver a capacidade leitora;

- propiciar o reconhecimento dos elementos que diferenciam um texto poético da prosa

- reconhecer, identificar e compreender o uso da linguagem figurada pelos poetas, bem como sua importância para a construção de sentidos do texto;

- reconhecer os elementos propiciadores da intertextualidade;

- propiciar o contato com diferentes autores com vistas à leitura e análise da temática dos poemas lidos;

- oportunizar o acesso a comentários feitos sobre poemas, bem como produzi-los para publicação online;

- analisar a temática dos poemas lidos e relacioná-la a sua própria experiência.

\begin{tabular}{|l|l|l|l|l|l|}
\hline $\begin{array}{l}\text { Agir social } \\
\text { e aspectos } \\
\text { contextuais }\end{array}$ & $\begin{array}{l}\text { Gêneros } \\
\text { Textuais } \\
\text { Centrais }\end{array}$ & $\begin{array}{l}\text { Atividade } \\
\text { Prática }\end{array}$ & $\begin{array}{l}\text { Aspectos } \\
\text { Críticos }\end{array}$ & $\begin{array}{l}\text { Aspectos } \\
\text { Tipológicos }\end{array}$ & $\begin{array}{l}\text { Aspectos Léxico- } \\
\text {-gramaticais }\end{array}$ \\
\hline $\begin{array}{l}\text { Perceber } \\
\text { a relação } \\
\text { entre } \\
\text { textos de } \\
\text { diferentes } \\
\text { esferas de } \\
\text { produção e } \\
\text { circulação }\end{array}$ & $\begin{array}{l}\text { Poema } \\
\text { Comen- } \\
\text { tário }\end{array}$ & $\begin{array}{l}\text { Produção e } \\
\text { postagem de } \\
\text { um comen- } \\
\text { tário acerca } \\
\text { de um dos } \\
\text { poemas } \\
\text { lidos no site } \\
\text { poemhunter. } \\
\text { com }\end{array}$ & $\begin{array}{l}\text { Desenvolver } \\
\text { a capacidade } \\
\text { leitora com } \\
\text { vistas à apre- } \\
\text { ciação, análise } \\
\text { e expressão } \\
\text { de opinião }\end{array}$ & $\begin{array}{l}\text { Narração e } \\
\text { Argumenta- } \\
\text { ção }\end{array}$ & $\begin{array}{l}\text { Classes gramaticias: } \\
\text { Verbos no passado } \\
\text { simples, pronomes, } \\
\text { adjetivos, organizado- } \\
\text { res textuais, modaliza- } \\
\text { dores. } \\
\text { Figuras e lingua- } \\
\text { gem: Metáfora, } \\
\text { ironia,sinédoque, } \\
\text { repetição }\end{array}$ \\
& & & & \\
\end{tabular}

19 Self-assessment. 


\begin{tabular}{|c|c|c|c|c|c|c|}
\hline GOALS & \multicolumn{3}{|c|}{ BEFORE STUDYING } & \multicolumn{3}{|c|}{ AFTER ATUDYING } \\
\hline I am able to... & YES & $\mathrm{NO}$ & PARTIALLY & YES & $\mathrm{NO}$ & PARTIALLY \\
\hline $\begin{array}{l}\text {...recognize and read poems ar } \\
\text { comments }\end{array}$ & & & & & & \\
\hline $\begin{array}{l}\text {...analyze the elementes that } \\
\text { compose poems and comment }\end{array}$ & & & & & & \\
\hline $\begin{array}{l}\text {...understand and use verbs in } \\
\text { different tenses and mode in } \\
\text { poems and comments }\end{array}$ & & & & & & \\
\hline ...recognize and listen to poen & & & & & & \\
\hline $\begin{array}{l}\text {...recognize and identify } \\
\text { figurative language used by } \\
\text { poets tocreate meaningful } \\
\text { poems }\end{array}$ & & & & & & \\
\hline $\begin{array}{l}\text {...recognize the way } \\
\text { intertextuality is built }\end{array}$ & & & & & & \\
\hline $\begin{array}{l}\text {...understand the importance } \\
\text { figurative language in poetry }\end{array}$ & & & & & & \\
\hline $\begin{array}{l}\text {...understand the elements tha } \\
\text { make a poetic text different } \\
\text { from a prose. }\end{array}$ & & & & & & \\
\hline $\begin{array}{l}\text {...produce a written comment } \\
\text { to be published on the net }\end{array}$ & & & & & & \\
\hline ...evaluate my own progress & & & & & & \\
\hline
\end{tabular}

Figura 2. SD Poetry: Reading beyond the words - apresentação de sua contextualização, seus objetivos, quadro sumário e self-assessment.

Fonte: material didático - Unidade: Poetry: Reading beyond the words.

Entendemos que a função dessa parte inicial da SD é de grande relevância para o desenvolvimento das próximas atividades que a compõem, pois, ao tomar conhecimento do todo, espera-se que o estudante possa compreender qual será o motivo para o seu agir social, ou seja, qual será a situação de comunicação em que agirá (DOLZ, NOVERRAZ, SCHNEUWLY, 2004).

Conforme PTG da SD em estudo, antes da produção inicial os estudantes entraram em contato com o contexto comunicativo do gênero poema, bem como estudaram sobre o gênero e seu contexto, para, em seguida, realizarem a produção inicial e as demais atividades que compõem a SD, envolvendo os módulos e as outras propostas de revisão e reescrita, totalizando três momentos de trabalho com foco na escrita. 
Justificamos, anteriormente, a opção por centrarmos nosso estudo na SD implementada no Ensino Superior, e, neste momento, faz-se relevante esclarecer que a produção escrita foi apenas um dos instrumentos avaliativos utilizados ao longo da implementação da SD. Além dela, P3 fez uso dos seguintes instrumentos de avaliação: prova de compreensão escrita com questões dissertativas; prova de compreensão oral com questões objetivas, composta pelos seguintes itens: resposta curta, lacuna, múltipla escolha (HAYDT, 2008) e produção individual de um vídeo, no qual cada aluno escolheu um poema, fez a sua leitura expressiva e teceu um comentário sobre ele.

A análise dos quadros 1, 2 e 3 revela que o trabalho com a escrita, instrumento avaliativo foco deste estudo, ocorreu, em cada uma das SD, em três momentos distintos: primeira produção, revisão e reescrita da primeira produção e produção final, o que vai ao encontro da nossa defesa de que a SD possibilita colocar em prática as modalidades avaliativas e suas funções que são: diagnosticar, controlar e classificar (HAYDT, 2008, FURTOSO, 2008). Além disso, os quadros evidenciam que há uma preocupação com o nível de escolarização dos estudantes, visto que é notória a diferença quanto à extensão das $\mathrm{SD}$, dos gêneros centrais e periféricos de cada uma delas e do grau de complexidade da proposta de ensino e aprendizagem.

\section{MODALIDADES AVALIATIVAS E AS ETAPAS DA SD: POSSÍVEIS CONTRIBUI- ÇÕES PARA O DESENVOLVIMENTO DAS CAPACIDADES DE LINGUAGEM}

$\mathrm{Na}$ apresentação da situação, os estudantes/acadêmicos, juntamente com a professora, fizeram um levantamento das possíveis razões para estudarem os gêneros de texto poema e comentário, sendo o último o selecionado para nossa investigação. Preencheram a lista de autoavaliação, bem como tomaram conhecimento das condições de produção para a realização da produção inicial.

A apresentação da situação, a autoavaliação e a produção inicial são compreendidas, por nós, como atividades que vão ao encontro da avaliação diagnóstica, por permitirem ao estudante se "enxergar" nesse processo e por ajudar o professor a direcionar as atividades futuras e a delimitar o conteúdo dos módulos.

A produção inicial ocorreu em sala de aula e teve como objetivo propiciar ao professor a obtenção de um diagnóstico acerca dos conhecimentos já adquiridos pelo estudante, bem como daqueles que ainda precisam ser ensinados, em relação à atividade de linguagem a ser realizada por ele. Isso aconteceu logo após a apresentação da situação, momento em que houve a explicitação acerca do contexto de produção 
para a realização da produção do gênero comentário. Antes da produção inicial, apresentamos os elementos contextuais: o emissor, o receptor, o local, o tempo, o papel social do emissor e do receptor, a instituição social e o objetivo da produção. Acordamos que a versão final seria publicada na internet, conforme indica a Figura 3.

\begin{tabular}{|c|c|c|c|c|c|c|}
\hline \multicolumn{4}{|c|}{ PoemHunter.com } & \multicolumn{2}{|c|}{ Search in poems, poets and quotations } & \multirow[t]{2}{*}{ Find } \\
\hline Home & Poems & Poets & Member Area & Quotations & Poetry E-Books & \\
\hline
\end{tabular}

$$
\begin{aligned}
& \text { Our database contains } 1,333,561 \text { poems from } 124,112 \text { poets. } 64,235 \text { Quotations. } \\
& \text { Search for : the road not taken } \\
& \text { Top searches: love, robert frost, shel silverstein, maya angelou, birthday, life }
\end{aligned}
$$

Figura 3. Página para postagem da produção final

Fonte:http://www.poemhunter.com/search/?q=the+road+not+taken

Dolz, Noverraz, Schneuwly (2004, p. 102) argumentam que a produção inicial propicia ao estudante condições de "descobrir o que já sabem fazer e conscientizar-se dos problemas que eles mesmos, ou outros estudantes, encontram", sendo, portanto, considerada por eles condizente com a avaliação formativa. Nós corroboramos esse entendimento, desde que levada em consideração função primeira de diagnosticar, conforme já apontamos anteriormente.

Para a realização da produção inicial, os estudantes tiveram como elemento de mediação o comando que segue:

\section{WORKING ON YOUR TEXT PRODUCTION}

You have read the poem "The road not taken" and something about the author. Write a comment about it!

Figura 4. Comando da produção inicial Fonte: material didático - Unidade: Poetry: Reading beyond the words.

Ao final da aula, P3 recolheu o texto produzido pelos acadêmicos para leitura a fim de avaliar "as capacidades já adquiridas e ajustar as atividades e exercícios previstos na SD às possibilidades e dificuldades reais" da turma (DOLZ, NOVERRAZ, SCHNEUWLY, 2004, p. 98). Essa prática vai ao encontro do que Haydt (2008) e Luckesi (2002) discutem como sendo inerente à avaliação diagnóstica. O esquema, a seguir, ilustra a realização desta etapa. 


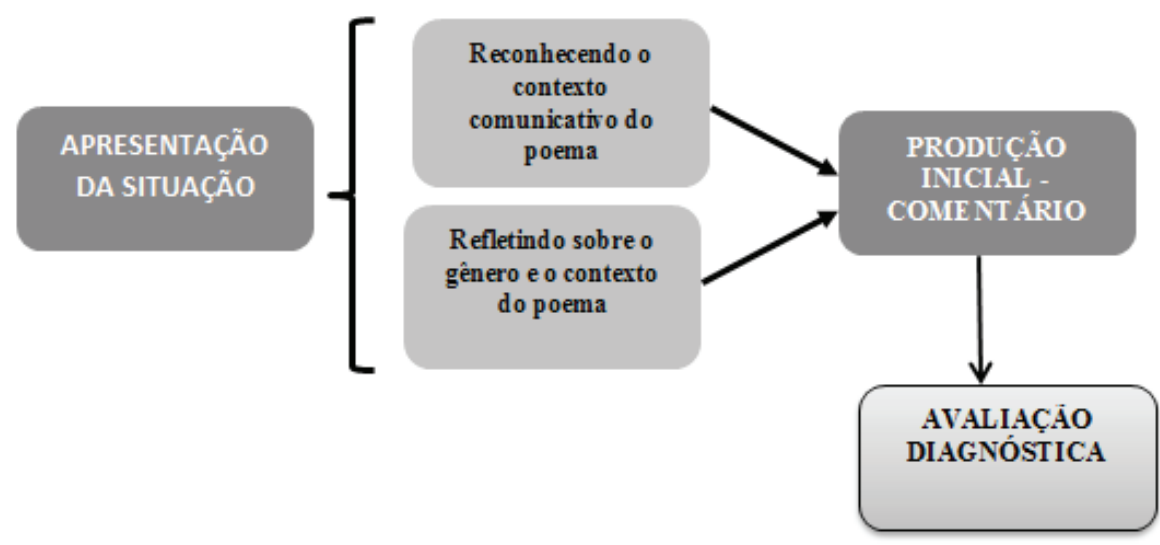

Esquema 1. Trajeto para a avaliação diagnóstica

Fonte: as autoras.

Entendemos ser possível estabelecer uma relação entre o que é defendido como inerente à função da avaliação diagnóstica e à produção inicial, conforme apresentado no quadro a seguir:

\section{Quadro 5. Avaliação diagnóstica X Produção inicial na SD}

\begin{tabular}{|c|c|}
\hline Avaliação diagnóstica & Produção Inicial na SD \\
\hline $\begin{array}{l}\text { - } \text { constitui-se em uma avaliação iniciali } \\
\text { - tem como objetivo identificar como o estu- } \\
\text { dante se encontra em relação ao assunto a } \\
\text { ser trabalhado; } \\
\text { - auxilia o professor na seleção dos conheci- } \\
\text { mentos e habilidades que deverão ser revi- } \\
\text { sitados antes da apresentação de conteúdos } \\
\text { novos; } \\
\text { - permite a identificação de variáveis que } \\
\text { possam interferir na aprendizagem, seja de } \\
\text { natureza cognitiva e/ou afetiva, } \\
\text { - possibilita ao professor definir, com maior } \\
\text { clareza, o ponto de partida mais adequado }\end{array}$ & $\begin{array}{l}\text { - permite avaliar as capacidades já adquiridas e } \\
\text { ajustar as atividades e os exercícios previstos } \\
\text { na sequência às possibilidades e dificuldades } \\
\text { da turma; } \\
\text { - define as capacidades que o estudante deve } \\
\text { desenvolver para melhor dominar o gênero de } \\
\text { texto em questão; } \\
\text { - serve como ponto de partida da sequência, } \\
\text { na medida em que evidencia as capacidades já } \\
\text { existentes e também as dificuldades apresen- } \\
\text { tadas pelo estudante. }\end{array}$ \\
\hline
\end{tabular}

Fonte: as autoras com base nos textos de Haydt (2008, p. 292); Souza (2012, p. 239) e Dolz, Noverraz e Schneuwly (2004, p. 98-107) 
Com base no Quadro 5, a produção inicial avaliada por P3 permitiu diagnosticar que o estudante participante deste estudo apresentou dificuldade quanto à representação da situação de comunicação, à elaboração dos conteúdos, ao planejamento do texto e à produção do texto.

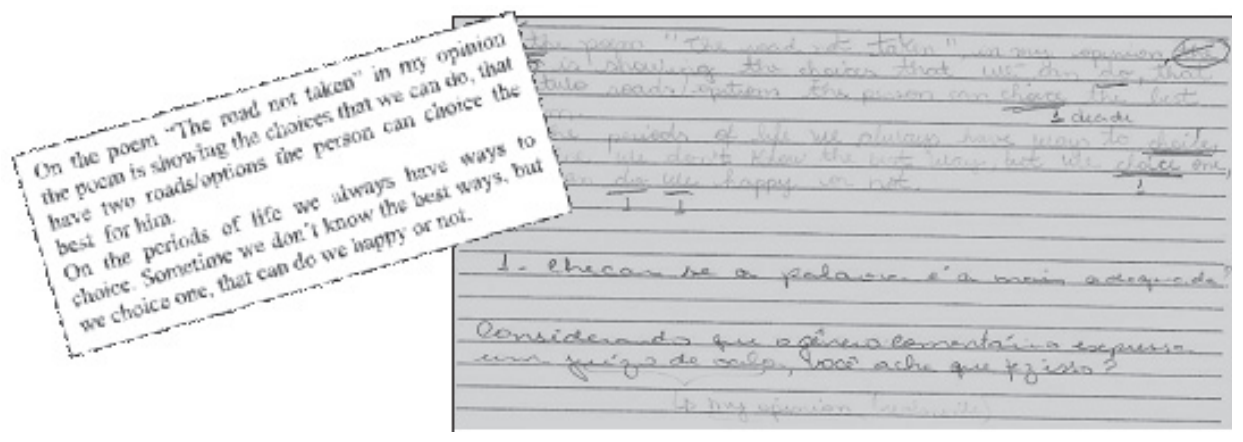

Figura 5. Produção inicial

Fonte: primeira versão produzida pelo estudante com os apontamentos da professora.

No tocante às capacidades de linguagem, esse diagnóstico demonstra que o estudante deixou de atender ou atendeu parcialmente aos seguintes critérios: 2CA, 4CA, 1CD, 2CD, 3CD , 4CD, 1CLD, 2CLD, 3CLD, 6CLD, 8CLD, 1CS, 4CS, 6CS, 7CS, em consonância com o apresentado no Quadro 1.

Em função das dificuldades apresentadas, P3 fez apontamentos mais gerais, tendo em vista que o objetivo era contribuir com o estudante no sentido de instigálo a produzir o gênero Comentário de maneira a atender à situação de comunicação proposta.

Após a produção inicial, conforme mencionado na seção que trata da SD, realiza-se o trabalho com os módulos, cujo objetivo é oferecer ao estudante instrumentos capazes de contribuir para a superação dos problemas evidenciados na produção inicial (DOLZ, NOVERRAZ, SCHNEUWLY, 2004). Na SD em foco os módulos dividem-se em: reconhecendo o contexto comunicativo; refletindo sobre o gênero e o contexto; refletindo sobre o conteúdo e o contexto e refletindo sobre a língua. Consideramos relevante mencionar que esses módulos compreendem atividades de diferentes campos, tais como motivacionais, enunciativos, procedimentais, textuais, linguísticos e também aquelas relacionadas à apropriação do sistema de escrita (NASCIMENTO, 2009).

Ao longo do processo de ensino e aprendizagem com a SD, de acordo com as atividades dos módulos, o estudante volta para a produção inicial, revisando e 
reescrevendo-a. Nesse caso, foram trabalhados nove módulos e, só depois disso, os estudantes receberam a produção inicial, com os apontamentos feitos pela professora, para, então, revisá-la e reescrevê-la, orientando-se também pelos elementos da lista de constatação ${ }^{20}$.

O processo de realização das atividades dos módulos, bem como a ação de revisar e reescrever o texto nos permitem compreender essas etapas como sendo pertencentes à avaliação formativa, conforme defendida por Haydt (2008).

A fim de ilustrar como os módulos foram organizados, apresentamos a sua distribuição no Esquema que segue:

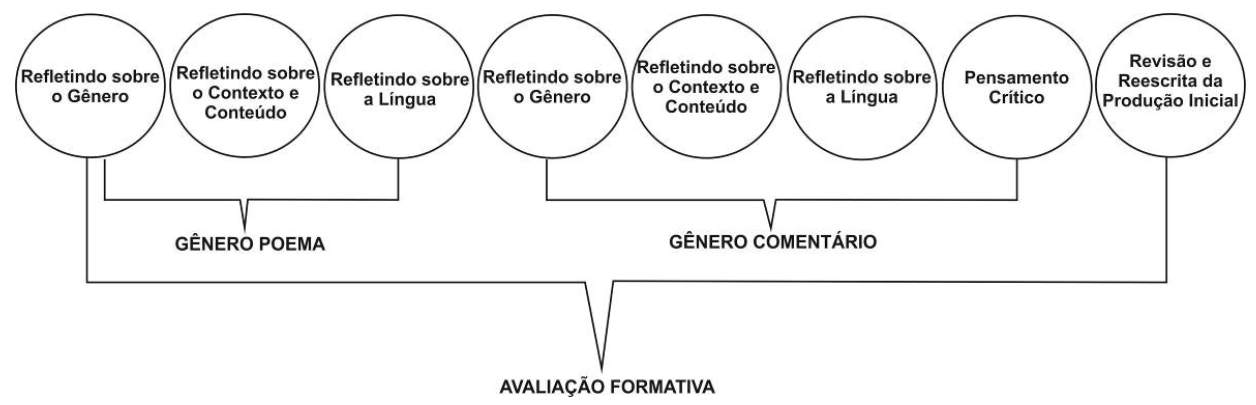

Esquema 2: organização dos módulos da SD

Fonte: as autoras.

O Esquema 2 ilustra que dos módulos trabalhados antes da segunda atividade de escrita, considerada por nós como parte da avaliação formativa, três deles foram dedicados ao estudo do poema e quatro ao estudo do comentário. Os três primeiros objetivavam contribuir com os estudantes no sentido de fornecer elementos para que pudessem (re) planejar a revisão e reescrita de seu texto. Os outros quatro, com foco no comentário, tinham como propósito colocar os estudantes em contato com o que seria necessário para que pudessem voltar à primeira produção, observando em que medida seu texto atendia à finalidade, aos interlocutores, às características discursivas do gênero, ao suporte, ao meio de circulação, à forma escolhida para posicionar-se e à delimitação do tema (MENEGASSI, 2012).

Assim, com o intuito de "trabalhar os problemas que apareceram na primeira produção e dar aos estudantes os instrumentos necessários para superá-los"

20 Dentre os instrumentos didáticos de regulação do processo de expressão escrita, estão as listas de controle ou listas de constatação, as quais elencam em forma de notas, aspectos discursivos, linguístico-discursivos com os quais o aluno vai entrando em contato durante as atividades de aprendizagem e "que podem ajudá-lo, como uma espécie de memória externa (agenda), na escrita de um novo texto." (PASQUIER; DOLZ, 1996). 
(DOLZ, NOVERRAZ E SCHNEUWLY, 2004, p. 103), organizamos atividades de observação e de análise de textos, tarefas simplificadas de produção de texto e a elaboração de uma linguagem comum, procurando atender ao que os autores supracitados sugerem como atividades capazes de aumentar as chances de sucesso no momento da produção textual. Apresentamos, a seguir, alguns comandos de atividades dos módulos, que tinham como propósito colaborar para que os problemas identificados fossem superados.

Read the following texts and check some opinions about the poem "The road not taken".

Point the reasons why "The road not taken" is one of the writer's favorite poem.

What is the writer's opinion about the poem message? Justify.

What is the writer opinionated about the poenm subject?

What words were uded to indicate the readers/writers liked the poem? What are their functions in a text?

Choose, from the words given, the adequate ones to complete the following paragraphs.

Figura 6. Exemplos de comandos dos módulos da SD

Fonte: material didático - Unidade: Poetry: Reading beyond the words.

As atividades apresentadas vão ao encontro da função dos módulos, bem como da necessidade dos estudantes, nesse caso, representada pela produção em estudo, pois todas elas estão relacionadas aos critérios das capacidades de linguagem. Como parte do processo de escrita, durante a realização dos módulos, devolvemos a produção inicial à turma para que pudesse revisá-la e reescrevê-la, com base nos apontamentos da professora, bem como com base nos critérios apontados no comando da atividade. A Figura 7 apresenta o comando da revisão e reescrita:

\section{WORKING ON YOUR TEXT PRODUCTION}

You have been in contact with different COMMENTS. Considering the information that you have been exposed to, get ready to analyze your own COMMENT. Does it have the author's name? Does it present the author's point of view? Does it present the author's conclusion? If something is missing, make all the necessary changes.

Figura 7. Comando da revisão e reescrita da produção inicial Fonte: material didático - Unidade: Poetry: Reading beyond the words.

Advogamos que a prática de revisão e reescrita é essencial para o atendimento do esperado da função formativa da avaliação que, segundo Haydt (2008), aproximase do mecanismo de feedback, pois possibilita tanto ao estudante quanto ao professor 
repensarem as práticas do processo de ensino e aprendizagem. Compreendemos essa atividade como parte da função formativa devido ao fato de que além dos apontamentos da professora, da lista de constatação, ainda havia o comando da atividade orientando o estudante sobre os aspectos que deveriam ser observados no momento da revisão e da reescrita, conforme apresentado. O quadro que segue nos permite visualizar as semelhanças entre as funções da avaliação formativa, de forma geral, e aquelas da avaliação formativa na SD.

\section{Quadro 6. Avaliação formativa X Avaliação formativa na SD}

\begin{tabular}{|c|c|}
\hline Avaliação formativa & Avaliação formativa na SD \\
\hline 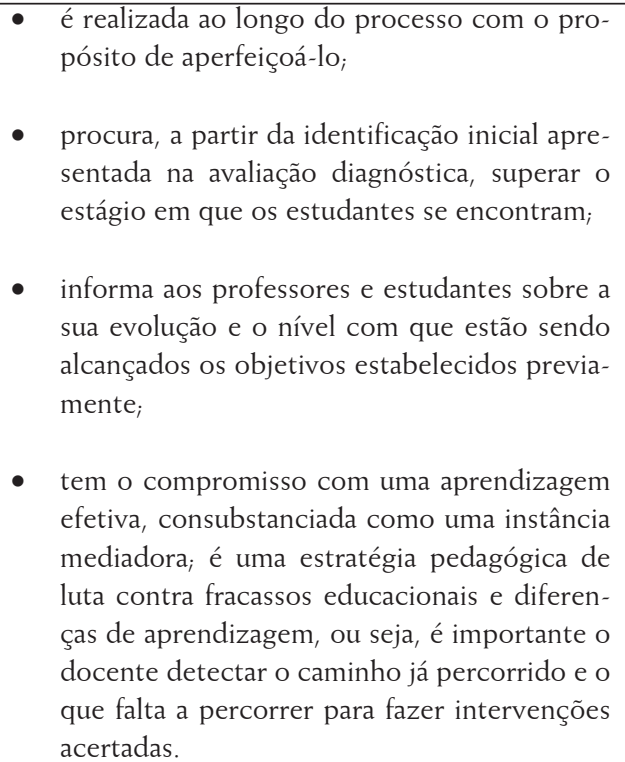 & $\begin{array}{l}\text { - } \text { é utilizada ao longo do processo; } \\
\text { - } \quad \text { tem como propósito aperfeiçoar o conhe- } \\
\text { cimento/processo; } \\
\text { - } \quad \text { informa os professores e estudantes sobre } \\
\text { a sua evolução e o nível com que estão } \\
\text { sendo alcançados os objetivos preestabe- } \\
\text { lecidos; } \\
\text { - possibilita a retomada da produção inicial, } \\
\text { seja ela oral ou escrita; } \\
\text { propicia a realização de outras atividades } \\
\text { avaliativas durante a aplicação dos módu- } \\
\text { los; centra-se na aprendizagem do gêne- } \\
\text { ro em estudo e no desenvolvimento das } \\
\text { capacidades de linguagem, ao invés de } \\
\text { centrar-se em aspectos quantitativos da } \\
\text { primeira versão. }\end{array}$ \\
\hline
\end{tabular}

Fonte: as autoras com base nos textos de Haydt (2008, p. 292), Souza (2012, p. 239) e Dolz, Noverraz e Schneuwly (2004, p. 98-107)

Considerando a função da avaliação formativa apresentada no quadro anterior, principalmente no tocante ao aperfeiçoamento do conhecimento ao longo do processo, a produção inicial após a revisão e reescrita evidencia que houve ampliação do conhecimento, visto que os apontamentos, feitos por $\mathrm{P} 3$ na produção inicial, foram atendidos.

No entanto, ao analisarmos a segunda versão - revisão e reescrita da produção inicial, percebemos outras dificuldades do estudante, as quais geraram novos apontamentos feitos por P3. 
O que segue ilustra esta etapa do processo.

\begin{abstract}
I loved this poem. (Very) nice, became) one of my favorites. The poem shows that we have choices in life and that we should choose what is best for us. Robert Frost had to make the decision about which road he would go down in life. Both ways could have a satisfactory result, but only one was chosen. I believe that in some periods of my life I always have to choose what's best for me, or at least, try trying to pick what I think will be best]. Because (what) I choose for sure will make me happy.
\end{abstract}

\begin{tabular}{l} 
[M1] Comentário: Falta o pronome \\
referente ao poema e o verbo to be no \\
presente simples 3 za pessoa. \\
[M2] Comentário: O pronome. \\
[M3] Comentário: Rafa, parece-me que \\
o must caberia melhor. O que você acha? \\
Falo isso pela concordância como verbo to \\
be na sequência. \\
[M4] Comentário: Com o superlativo \\
devemos usar o artigo definido, lembra? \\
[M5] Comentário: Rafa, você se lembra \\
que o eu lírico do poema não era o Erost? \\
[M6] Comentário: THE ou A? \\
[M7] Comentário: Parece-me queo \\
sentido aqui seria SEGUIR. É isso? Se for, \\
ficará melhor CHOOSE. \\
[M8] Comentário: Mesma situaçãoo \\
comentário 4. \\
\hline $\begin{array}{l}\text { [M9] Comentário: Mesma situação do } \\
\text { comentário 4. }\end{array}$ \\
[M10] Comentário: Certifique-se da \\
pontuação. Ela é necessária?
\end{tabular}

[M1] Comentário: Falta o pronom presente simples $3^{2}$ pessoa.
pres.

[M3] Comentário: Rafa, parece-me que must caberia melhor. 0 que você acha? be na sequência.

M4] Comentário: Com o superlativo devemos usar o artigo definido, lembra? [M5] Comentário: Rafa, você se lembra
que o eu lírico do poema não era o Erost? [M6] Comentário: THE ou A? ficará melhor CHOOSE.

Comentário: Mesma situação。

M9] Comentário: Mesma situação do

[M11] Comentário: O que você ac

Figura 8. Segunda versão do texto produzido pelo estudante

Fonte: produção inicial revisada e reescrita pelo estudante a partir dos apontamentos da professora e do comando da atividade de escrita.

Nessa versão do texto, notamos que as dificuldades apresentadas centram-se nas capacidades linguístico-discursivas, pois se referem à utilização adequada de palavras, pronomes, artigos, verbos e adjetivos. Notamos também que a professora optou por não resolver os problemas identificados, mas sim por apontá-los, por questioná-los, exigindo que o estudante retomasse o conteúdo já trabalhado, inclusive em outras SD, para a realização da escrita da produção final.

Tal opção metodológica vai ao encontro do que Dolz, Noverraz, Schneuwly (2004, p. 103) apresentam como sendo função da avaliação formativa, no processo de escrita, visto que a produção, revisão e reescrita constituem-se como "[...] um momento de conscientização do que está em jogo e das dificuldades relativas ao objeto de aprendizagem [...] os pontos fortes e fracos são evidenciados [...] são buscadas soluções para os problemas que aparecem".

Com o intuito de avaliar se os módulos contribuíram para a solução dos problemas detectados em relação às capacidades de linguagem do estudante, analisamos a revisão e reescrita da primeira produção a partir dos critérios que não tinham sido atendidos na primeira versão da produção inicial.

Tal análise evidenciou que houve o atendimento aos apontamentos feitos por $\mathrm{P} 3$, bem como uma ampliação em relação às capacidades de linguagem. No 
entanto, como já mencionado, nessa versão o estudante apresentou, de forma mais acentuada, dificuldades que dizem respeito às capacidades linguístico-discursivas, em especial, aos critérios 3CLD, 4CLD, 5CLD e 6CLD.

Considerando a necessidade do registro dos conhecimentos adquiridos pelos estudantes ao longo da SD, a fim de capitalizar as aquisições dos estudantes, conforme apontado por Dolz, Noverraz, Schneuwly (2004, p. 107), utilizamos a lista de constatação, desde a segunda versão do texto, devido ao fato de que ela possibilita ao estudante: i) controlar o seu próprio processo de aprendizagem; ii) regular e controlar sua produção escrita; iii) avaliar os progressos realizados no domínio trabalhado.

A figura que segue expressa a autoavaliação realizada pelo estudante, indicando a maturidade do mesmo em relação ao processo de escrita, revisão e reescrita, ou seja, expressa o processo inerente à modalidade da avaliação formativa.

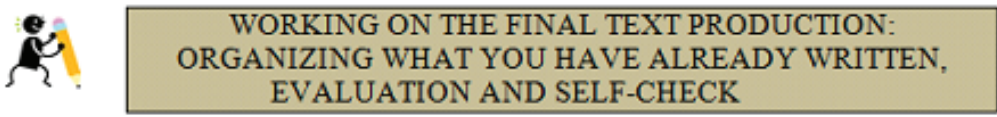

1-Analyze the comment you wrote using the checklist below.

\begin{tabular}{|c|c|c|c|}
\hline & YES & NO & PARTIALLY \\
\hline Is your comment about a remarkable poem? & $x$ & & \\
\hline Is the theme of the poem relevant to you? & $\bar{Y}$ & & \\
\hline Do you express your opinion? & 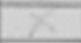 & & \\
\hline Is there a name/nickname? & & & \\
\hline Is there an analysis of the poem content? & 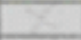 & & \\
\hline Is your point of view supported? & & & \\
\hline Does your comment evaluate specific features of the poem? & & & $x$ \\
\hline Is there a conclusion? & $X$ & & \\
\hline Do you make use of adequate pronouns? & & & \\
\hline Do you use adequate verb tenses? & $x$ & & \\
\hline Do you use adequate adjectives? & $\zeta$ & & \\
\hline Do you use words to indicate modality in an appropriate way? & & 8 & \\
\hline Are spelling and punctuation used in a correct way? & & & 8 \\
\hline
\end{tabular}

1- Review your draft and rewrite it, if you ticked NO or PARTIALLY for some item(s).

Figura 9. Lista de constatação

Fonte: material didático do estudante.

Na lista de constatação percebemos que, embora ele tenha realizado a produção escrita em diferentes momentos, seguindo os apontamentos da professora, o texto antes da versão final ainda deixara de atender a três dos itens considerados 
relevantes para o gênero em foco, os quais estão relacionados às capacidades de ação, capacidades de significação e capacidades linguístico-discursivas.

Ao retomarmos à associação entre as etapas da $\mathrm{SD}$ e as modalidades avaliativas, nos reportamos a avaliação somativa, que em nosso caso ocorreu no final da implementação da SD e teve como objetivo colocar em prática o que é apresentado no quadro que segue:

\section{Quadro 7. Avaliação somativa X Avaliação somativa na SD}

\begin{tabular}{|c|c|}
\hline Avaliação somativa & Avaliação somativa na SD \\
\hline $\begin{array}{l}\text { - é realizada ao final de um processo; } \\
\text { - propicia um levantamento global do grau } \\
\text { em que os objetivos mais abrangentes foram } \\
\text { alcançados; } \\
\text { - é o momento em que os resultados são } \\
\text { traduzidos em notas ou conceitos; } \\
\text { - presta-se à comparação de resultados obtidos } \\
\text { com diferentes alunos, métodos e materiais de } \\
\text { ensino; } \\
\text { - pode coexistir com todas as outras modalidades } \\
\text { de avaliação; } \\
\text { - é necessária para que o sistema educacional } \\
\text { apresente os resultados obtidos ao término } \\
\text { e/ou durante o processo de ensino e } \\
\text { aprendizagem (retorno à sociedade). }\end{array}$ & $\begin{array}{l}\text { - é realizada com base na produção final; } \\
\text { - dá ao aluno a possibilidade de colocar em } \\
\text { prática as noções e instrumentos elaborados } \\
\text { separadamente nos módulos; } \\
\text { - permite ao professor e ao aluno, por meio } \\
\text { da lista de constatação, a explicitação dos } \\
\text { critérios de avaliação em uma linguagem } \\
\text { comum; } \\
\text { - indica os pontos essenciais adquiridos, ou } \\
\text { não, pelos estudantes; } \\
\text { - possibilita ao professor realizar uma } \\
\text { avaliação mais objetiva com base nos } \\
\text { critérios elaborados ao longo da SD. }\end{array}$ \\
\hline
\end{tabular}

Fonte: as autoras com base nos textos de Haydt (2008, p. 292), Souza (2012, p. 239) e Dolz, Noverraz e Schneuwly (2004, p. 98-107).

Entendemos que, embora a avaliação somativa resulte em uma classificação (HAYDT, 2008), também vá ao encontro da avaliação formativa, visto que, no momento da produção final, é requerida do estudante uma tomada de consciência sobre os aspectos trabalhados ao longo da implementação da SD. Ilustramos essa etapa com a produção final publicada pelo estudante, conforme contrato firmado na apresentação da situação. 


\section{Rafael Zeferino (7/27/2014 10:54:00 PM)}

I loved this poem. It's very nice, It became one of my favorites. The poem shows we have choices in life and that we must choose which is the best for us. The lyrical I, he had to make a decision about which road he would choose in life. Both ways could have a satisfactory result, but only one was chosen. I believe that in periods of my life I always have to choose which the best for me, or at least, try to pick what I think will be the best because whatever I choose for sure will make me happy. Rafah - Brazil | Delete this message

\section{Figura 10. Produção final}

Fonte: disponível em <http://www.poemhunter.com/poem/the-road-not-taken/comments/ page-8/> acesso em 04/01/2016

A produção final publicada pelo estudante revela que houve avanço quanto ao atendimento dos critérios das capacidades de linguagem, pois, os apontamentos / questionamentos de P3 foram atendidos. Ressaltamos que tais apontamentos tinham como objetivo fazer o estudante retomar aspectos já estudados em outros momentos e os resultados indicam que tal objetivo foi atingido. Entendemos que nessa etapa o estudante "pode pôr em prática os conhecimentos adquiridos e, com o professor, medir os progressos alcançados" (DOLZ; NOVERRAZ; SCHNEUWLY, 2004, p. 98-99).

O Esquema, a seguir, ilustra como estabelecemos a relação entre as diferentes etapas da SD e modalidades avaliativas.

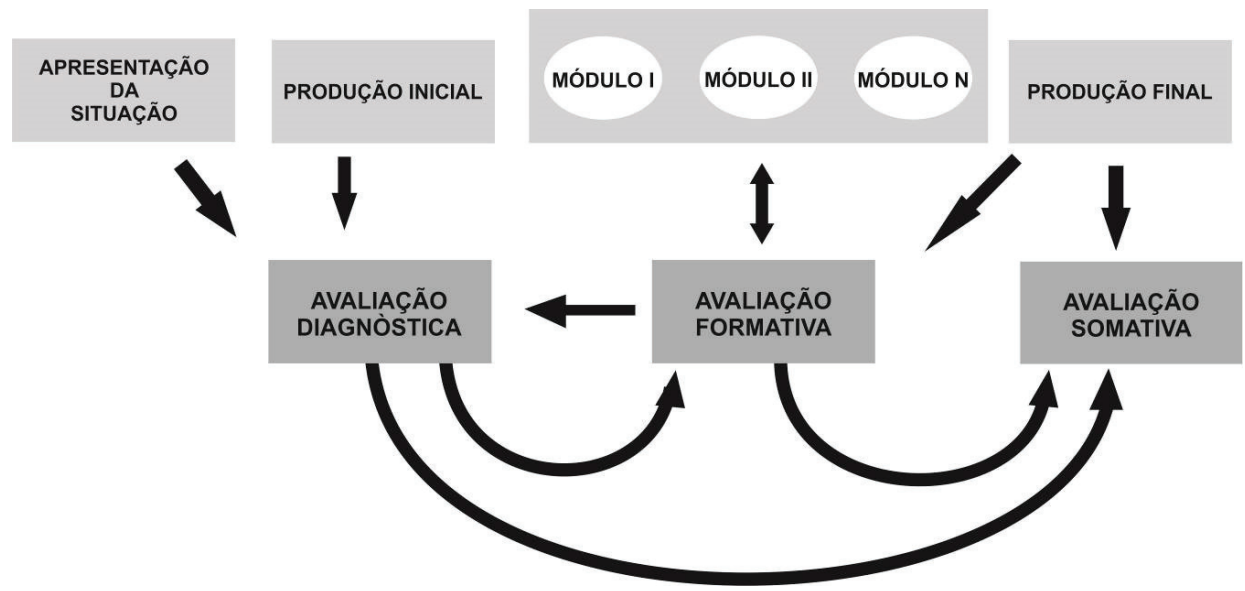

Esquema 3. Etapas da SD e suas relações com as modalidades avaliativas

Fonte: as autoras. 
As articulações realizadas por nós entre as etapas da produção escrita/oral de uma SD e as modalidades da avaliação corroboram a nossa defesa de que as diferentes etapas da SD vão ao encontro das modalidades de avaliação: diagnóstica, formativa e somativa, pois a produção final publicada pelo estudante evidencia a concepção de avaliação defendida por Dolz, Noverraz e Schneuwly (2004, p. 108), a qual é entendida como "uma questão de comunicação e de trocas. [...] ela orienta os professores para uma atitude responsável, humanista e profissional".

\section{ALGUMAS CONSIDERAÇÕES}

A perspectiva teórico-metodológica norteadora do estudo por nós realizado vai ao encontro das necessidades prementes quanto à efetivação das diferentes funções da avaliação no processo de ensino e aprendizagem, uma vez que o procedimento SD demonstra ser um instrumento possibilitador para colocá-las em prática.

Além disso, a SD permite ao professor o acompanhamento das produções de seus estudantes, no sentido de identificar se houve o avanço esperado, se seus objetivos foram atingidos ou se ainda há necessidade de retomar alguns aspectos, atendendo, portanto, o que deveria ser a principal função da avaliação, ou seja, orientar e reorientar o processo de ensino e aprendizagem.

Os resultados obtidos por esse estudo podem ser atribuídos aos contextos de implementação da pesquisa, os quais possibilitaram a implementação das SD em todas as suas etapas, bem como a efetivação das três modalidades de avaliação, considerando as particularidades de cada contexto, a saber: i. uma SD implementada em uma turma de $8^{\circ}$ ano do Ensino Fundamental, com a presença da professora regente e duas acadêmicas de Letras participantes do PIBID; ii. uma SD implementada no CELEM, com turmas constituídas por no máximo 20 estudantes; iii. uma SD implementada em uma turma de $3^{\circ}$ ano do curso de Letras Português/ Inglês, a qual era dividida em dois grupos de aproximadamente 15 estudantes.

Temos ciência da relevância de um trabalho nesse viés para a formação do indivíduo e para a qualidade de ensino, contudo, as condições objetivas de trabalho dos contextos de ensino da Educação Básica e Ensino Superior, em sua maioria, não contribuem para a viabilização de um trabalho com tamanha exigência. Tal compreensão reforça a necessidade de Políticas Públicas para a Educação capazes de propiciar condições favoráveis a um ensino efetivo e de qualidade. 
Diante disso, reforçamos que o intento desse estudo foi apontar algumas possibilidades de práticas pedagógicas que possam contribuir para uma mudança no quadro vigente no tocante à avaliação, bem como indicar a necessidade de expansão nos estudos da área.

\section{REFERÊNCIAS BIBLIOGRÁFICAS}

BAZERMAN, C. (1988/2000). Shaping Written Knowledge: The Genre and Activity of the Experimental Article in Science. WAC Clearing house Landmark Publications in Writing Studies: http://wac.colostate.edu/books/ bazerman_shaping/ Originally Published in Print, by University of Wisconsin Press, Madison, Wisconsin. Disponível em: <http:// wac.colostate.edu/books/bazerman_shaping/chapter1.pdf $>$ Acesso em: 17 jun. 2015.

BEATO-CANATO, A.P.M. (2009). O desenvolvimento da escrita em língua inglesa com o uso de sequências didáticas contextualizadas em um projeto de troca de correspondências. Tese de Doutorado em Estudos da Linguagem. Universidade Estadual de Londrina, Londrina. Disponível em: <http://www.bibliotecadigital.uel.br/document/? code=vtls000151181\&print $=\mathrm{y}>$. Acesso em: 04 mar. 2014.

BLOOM, B. et al. (1983). Manual de Avaliação Formativa e Somativa do Aprendizado Escolar, trad. Lilian Rochlitz Quintão; Maria Cristina Fioratti Florez; Maria Eugênia Vanzolini. São Paulo: Livraria Pioneira Editora.

BONESI, P.G.;SOUZA, N.A. de. (2006). Fatores que dificultam a transformação da avaliação na escola. Estudos em Avaliação Educacional. v. 17, nº 34, pp. 129-153.

Disponível em: < http://www.fcc.org.br/pesquisa/publicacoes/eae/arquivos/1288/1288. pdf $>$ Acesso em: 10 out. 2015.

BRONCKART, J.P. (1999/2007/2012) Atividade de linguagem, textos e discursos: Por um interacionismo sociodiscursivo, trad. Anna Rachel Machado; Péricles Cunha. $2^{\mathrm{a}}$ ed. São Paulo: EDUC.

BRONCKART, J.P. (2006) Interacionismo Sócio-discursivo: uma entrevista com Jean Paul Bronckart. Tradução de Cassiano Ricardo Haag e Gabriel de Ávila Othero. Revista Virtual de Estudos da Linguagem - ReVEL. v. 4, nº 6. Disponível em: < http://www.revel. inf.br/files/entrevistas/revel_6_entrevista_bronckart_port.pdf $>$. Acesso em: 14 out. 2013.

CHEVALLARD, Y. (1989).On didactic transposition theory: some introductory notes. Disponível em: $<$ http://yves.chevallard.free.fr/spip/spip/rubrique.php3 ?id_rubrique $=6>$. Acesso em: 17 jan. 2015.

CHUEIRI, M. S. F. (2008) Concepções sobre a Avaliação Escolar. Estudos em Avaliação Educacional.v. 19, n 39, pp. 49-64. Disponível em: < http://www.fcc.org.br/pesquisa/ publicacoes/eae/arquivos/1418/1418.pdf $>$ Acesso em: 20 nov. 2015. 
CRISTÓVÃO, V. L. L. (2007). Procedimentos de Análise e Interpretação em textos de avaliação. In: Guimarães, A. M. Mi Machado, A. R.; Coutinho, A. (org.), O Interacionismo Sociodiscursivo: questões epistemológicas e metodológicas. $1^{\mathrm{a}}$ Ed. Campinas: Mercado de Letras. pp. 257-272.

CRISTÓVÃO, V. L. L.; et. al. (2010). Uma proposta de planejamento de ensino de língua inglesa em torno de gêneros textuais. Letras. v. 20, nº 40, pp. 191-215.

CRISTÓVÃO, V. L. L.; STUTZ, L. (2011). A Construção de uma Sequência Didática na Formação Docente de Língua Inglesa. Revista SIGNUM: Estudos da Linguagem. V. 14. $\mathrm{n}^{\circ} 1$, pp.569-589.

CONSOLO, D. A. (2004) A construção de um instrumento de avaliação da proficiência oral do professor de língua estrangeira. Trabalhos em Linguística Aplicada (UNICAMP), Campinas-SP, v. 43, n.2, p. 265-286.

DENARDI, D.A.C. (2009). Flying together towards EFL teacher development as language learners and professionals through genre writing. Tese de Doutorado em Letras - Inglês e Literatura Correspondente. Universidade Federal de Santa Catarina, Florianópolis. Disponível em: < https://repositorio.ufsc.br/xmlui/handle/123456789/92491> Acesso em: 25 fev. 2015.

DOLZ, J; GAGNON, R; DECÂNDIO, F. (2010). Produção escrita e dificuldades de aprendizagem, trad. Fabrício Decândio; Anna Rachel Machado. Campinas: Mercado das Letras.

DOLZ, J.; NOVERRAZ, M.; SCHNEUWLY, B. (2004). Sequências Didáticas para o oral e a escrita: apresentação de um procedimento. In: Schneuwly, B, Dolz, J. et. al. Gêneros orais e escritos na escola, trad. Roxane Rojo; Glaís Sales Cordeiro. Campinas: Mercado de Letras.

DOLZ, J.; SCHNEUWLY, B. (2004). Gêneros e progressão em expressão oral e escrita elementos para reflexões sobre uma experiência suíça (francófona) In: Schneuwly, B; Dolz, J. et. al. Gêneros orais e escritos na escola, trad. Roxane Rojo; Glaís Sales Cordeiro. Campinas: Mercado de Letras.

FERRARINI, M. A. (2009). O gênero textual conto de fadas didatizado para o ensino de produção escrita em lingua inglesa. Dissertação de Mestrado em Estudos da Linguagem, Universidade Estadual de Londrina. Londrina. Disponível em: <http://www.bibliotecadigital.uel. $\mathrm{br} / \mathrm{document} /$ ? code $=\mathrm{vtl}$ s000152702 > . Acesso em: $20 \mathrm{mar}$. 2015.

FURTOSO, V. B. (2008). Interface entre avaliação e ensino-aprendizagem: desafios na formação de professores. In: Durão, A. B. A. B.; Andrade, O. G.; Reis, S. (org.), Reflexões sobre o ensino das línguas estrangeiras. Londrina: UEL, pp. 127-158.

GASPAROTTO, D. (2014). O trabalho colaborativo em práticas de revisão e reescrita de textos em séries finais do ensino fundamental I. Dissertação de Mestrado em Letras. Universidade Estadual de Maringá, Maringá. Disponível em: <http://www.ple.uem. br/defesas/pdf/dmgasparotto.PDF>. Acesso em: 24 set. 2015.

GONÇALVES, A.; NASCIMENTO, E. L. (2010). Avaliação formativa: autorregulação e controle da textualização. Trabalbos em Linguística Aplicada. v. 49, n 1, pp. 241-257. 
Disponível em: < http://www.scielo.br/pdf/tla/v49n1/16.pdf>. Acesso em: 20 ago. 2014.

HADJI, C. (1993). A avaliação, regras do jogo: das intenções aos instrumentos. 4. ed. Portugal: Porto Editora.

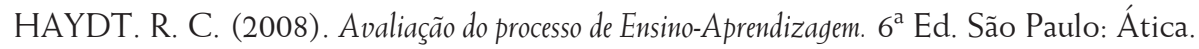

HOFFMANN, J. (1998). Pontos e contrapontos: do pensar ao agir em educação. Porto Alegre: Mediação.

LANFERDINI, P.A.F. (2012). O trabalbo (agir) docente no processo coletivo de planejamento e elaboração de uma Sequência Didática para o ensino de Lingua Inglesa. 2012. Dissertação de Mestrado em Estudos da Linguagem. Universidade Estadual de Londrina: Londrina. Disponível em: $\quad<$ http://www.bibliotecadigital.uel.br/document/?code=vtls000177959> . Acesso em: 20 mar. 2015.

LEAL, A.A. (2011). A organização textual do gênero cartoon: aspectos linguísticos e condicionamentos não linguísticos. Tese de Doutorado em Linguística - Teoria do Texto. Faculdade de Ciências Sociais e Humanas, Universidade Nova de Lisboa, Portugal. Disponível em: < http://run.unl.pt/handle/10362/6646> Acesso em: 13 jan. 2015.

LIBÂANEO, J. C.; ALVES, N. (2012). Temas de pedagogia: diálogos entre didática e currículo. São Paulo: Cortez.

LUCKESI, C. C. (2012). Avaliação da Aprendizagem na escola. In: Libâneo, José Carlos; Alves, Nilda (org.), Temas de pedagogia: diálogos entre didática e currículo. São Paulo: Cortez. pp. $433-451$.

LUCKESI, C. C. (2003). Avaliação da aprendizagem na escola: reelaborando conceitos e recriando a prática. Salvador: Malabares Comunicação e Eventos.

LUCKESI, C. C. (2006). Entrevista publicada na Folha Dirigida, Rio de Janeiro, Edição no 1069, no caderno "Aprender", pág. 9. Disponível em: < http://www.luckesi.com.br/ textos/entrevista_folha_dirigida_outubro2006.pdf $>$. Acesso em: 15 out.2015.

LUCKESI, C. C. (2002). Avaliação da Aprendizagem escolar: estudo e proposições. $14^{\text {a }}$ Ed. São Paulo: Cortez.

MARCONI, M.; LAKATOS, E. M. A. (2003). Metodologia científica. 5ª Ed. São Paulo: Atlas. MENEGASSI, R J. (2010). O processo de produção textual. In: Santos, A. R.; Greco, E. A.; Guimarães, T. B. A produção textual e o ensino. Formação de Professores em Letras EAD; $n^{\circ}$ 6. Maringá: EDUEM.

MENEGASSI, R J. (2012). Conceitos bakhtinianos em comandos de prova de redação. In: Figueiredo, D. C.; Bonini, A.; Furlanetto, M. M.; Moritz, M. E. W. (org.), Sociedade, cognição e linguagem: apresentações do IX CELSUL. Florianópolis: Insular. v. 1. pp. 251-276.

MINAYO, M. C. S. (2001). Pesquisa social: teoria, método e criatividade. Petrópolis: Vozes, 2001.

NASCIMENTO, E. L. (2009). Gêneros Textuais: da didática das línguas aos objetos de ensino. São Carlos: Editora Claraluz. 
PASQUIER, A.; DOLZ, J. (1996). Um decálogo para ensinar a escrever. Cultura y Educación, n. 2, p. 31-41, 1996. Disponível em: <http://pt.scribd.com/doc/65966212/Umdecalogo-para-ensinar-a-escrever-traducao-Roxane-Rojo $>$ Acesso em: 14 out. 2013.

PONTARA, C. (2015). Gêneros textuais e sequência didática propiciando um ensino significativo de análise linguística e expressão escrita em língua inglesa. Dissertação (Mestrado em Estudos da Linguagem) - Universidade Estadual de Londrina, PR.

RIBEIRO, E.A.G. (2011). Avaliação formativa em foco: concepção e características no discurso dicente. Dissertação (Mestrado em Educação) - Universidade Estadual de Londrina, PR. Disponível em: <http://www.uel.br/pos/mestredu/images/stories/downloads/ dissertacoes/2011/2011__RIBEIRO_Elizabete_Aparecida_Garcia.pdf $>$. Acesso em: 17 jan. 2016.

RIOS REGISTRO, E. S. (2013). O conto na interface língua, literatura de língua inglesa e formação de professor de língua inglesa: uma proposta mediada pela produção de sequências didáticas. Tese de Doutorado em Estudos da Linguagem. Universidade Estadual de Londrina. Londrina. Disponível em: <http://www.bibliotecadigital.uel.br/ document $/$ ? code $=$ vtls000189442> . Acesso em: 20 fev. 2015.

RUIZ, E.D. (2010/2013). Como corrigir redações na escola: uma proposta textual-interativa. $1^{\text {a }}$ Ed. $2^{\text {a }}$ reimpressão. São Paulo: Contexto.

SCARAMUCCI, M. V. R. (2011) Validade e consequências sociais das avaliações em contextos de ensino de línguas. Linguarum Arena, v. 2, p. 121-137.

SCARAMUCCI, M. V. R. (2014) A Avaliação no Ensino-Aprendizagem de Línguas e nas Pesquisas em Linguística Aplicada. In: MULIK, Katia Bruginski; RETORTA, Miriam Sester. (Org.). Avaliação no Ensino-Aprendizagem de Linguas Estrangeiras: Diálogos, Pesquisas e Reflexões. 1ed. Campinas: Pontes Editores, v. 1, p. 257-262.

SCHNEUWLY, B.; DOLZ, J. (2004). Gêneros orais e escritos na escola. trad. Roxane Rojo; Glaís Sales Cordeiro. Campinas: Mercado das Letras.

SCHNEUWLY, B. (2004). Gêneros e tipos de discurso: considerações psicológicas e ontogenéticas. In: Schneuwly, B; Dolz, J. et. al. Gêneros orais e escritos na escola, trad. Roxane Rojo; Glaís Sales Cordeiro. Campinas: Mercado de Letras.

SCRIVEN, M. (1967). The methodology of evaluation: perspectives on curriculum evaluation. AERA Monograph Series on Curriculum evaluation. $n^{\circ} .1$, Chicago Rand Mc-Nally. Disponível em: <http://www.comp.dit.ie/dgordon/Courses/ILT/ILT0005/ TheMethodologyOfEvaluation.pdf $>$. Acesso em: 10 set. 2015.

SILVA, D. P. (2011). A avaliação somativa nas sequências didáticas para o oral e escrita em Português. Dissertação de Mestrado em Letras. Universidade Federal do Pará, Belém. Disponível em: <http://repositorio.ufpa.br/jspui/handle/2011/4661>. Acesso em: 10 ago. 2014.

SILVA, E. L.; MENEZES, E. M. (2005). Metodologia da pesquisa e elaboração de dissertação. $4^{\text {a }}$ Ed. Florianópolis: UFSC. Disponível em: <https://projetos.inf.ufsc.br/arquivos/ 
Metodologia_de_pesquisa_e_elaboracao_de_teses_e_dissertacoes_4ed.pdf $>$ Acesso em: 27 de jan. 2016.

SOUZA, A. M. L. (2012). Avaliação de Aprendizagem no Ensino Superior: aspectos históricos. Revista Exitus. v. 2, n 1, pp. 231-254. Disponível em: < http://www.ufopa. edu.br/revistaexitus/revistas/volume-ii/artigos/avaliacao-da-aprendizagem-noensino-superior-aspectos-historicos/view >. Acesso em: 12 ago. 2014.

STUTZ, L. (2012). Sequências didáticas, socialização de diários, autoconfrontação: instrumentos para a formação inicial de professores de inglês. Tese de Doutorado em Estudos da Linguagem. Universidade Estadual de Londrina: Londrina.

SUASSUNA, L. Paradigmas de avaliação: uma visão panorâmica. In: MARCUSCHI B. e SUASSUNA L. (org.). Avaliação em língua portuguesa: contribuições para a prática pedagógica. 1ed., 1 reimp. Belo Horizonte: Autêntica, 2007. Disponível em: <http://www. serdigital.com.br/gerenciador/clientes/ceel/arquivos/8.pdf $>$. Acesso em: 02 fev. 2016.

VIGOTSKI, L.S. (2002). Pensamento e linguagem. Disponível em < http://www.institutoelo. org.br/site/files/publications/5157a7235ffccfd9ca905e359020c413.pdf $>$ Acesso em: 10 de agosto de 2014 .

Enviado: 11/04/2016

Aceito: $13 / 02 / 2017$ 